\title{
On the Early Response of the Climate System to a Meltwater Input from Greenland
}

\author{
NeERAJ Agarwal \\ Max Planck Institute for Meteorology, Hamburg, Germany \\ ARMIN KÖHL \\ University of Hamburg, Hamburg, Germany \\ CARlos Roberto Mechoso \\ Department of Atmospheric and Oceanic Sciences, University of California, Los Angeles, \\ Los Angeles, California \\ DetLAF STAMMER \\ University of Hamburg, Hamburg, Germany
}

(Manuscript received 10 December 2013, in final form 20 July 2014)

\begin{abstract}
The early response of the atmosphere-ocean system to meltwater runoff originating from the Greenland ice sheet is studied using a coupled atmosphere-ocean general circulation model (AOGCM). For this purpose, AOGCM ensemble simulations without and with associated ocean freshening around Greenland are compared. For freshwater perturbations initiated in northern winter, the mean response for the first three months shows the emergence of negative sea surface temperature (SST) anomalies in the Denmark Strait, in association with enhanced oceanic advection by the East Greenland Current. The response also shows negative SST anomalies in the North Atlantic associated with enhanced westerlies at the ocean surface. Additionally, the baroclinic atmospheric cyclonic circulation east of Greenland intensifies, and anticyclonic circulations with equivalent barotropic structures develop over western Europe and the North Pacific Ocean. Simulations by the atmospheric component of the AOGCM indicate that atmosphere-ocean interactions contribute significantly to enhance the response. The sensitivity of the coupled system response to the timing of freshwater perturbation is also studied. For freshwater perturbations initialized in northern summer, the response during the following winter is similar, but stronger in magnitude. In the Northern Hemisphere, the atmospheric response resembles the Arctic Oscillation (AO) mode of variability. The association between anomalies in the Denmark Strait SSTs and in the atmosphere east of Greenland is consistent with that observed during previous great salinity anomaly (GSA) events. The results obtained highlight the importance of atmosphere-ocean interaction in the early climate response to Greenland melting, the teleconnections with the North Pacific and the contribution of GSA events to North Atlantic Oscillation (NAO) variability.
\end{abstract}

\section{Introduction}

Future anthropogenic warming of the planet is projected to be especially strong in the polar regions of the Northern Hemisphere (Stocker et al. 2014). Significant changes are already occurring in these regions. Arctic sea ice, for example, has been continuously declining

Corresponding author address: Neeraj Agarwal, Max Planck Institute for Meteorology, 53 Bundestrasse, Hamburg, Germany 20146.

E-mail: neeraj.agarwal@zmaw.de with record low values in extent recorded during 2007 and 2012 (Perovich et al. 2013). Simultaneously, the Greenland Ice Sheet (GIS), one of the largest ice masses in the world, has been melting at an increasing rate since about a decade ago (Shepherd et al. 2012). Only little is known about the mass balance of this ice sheet before the 1990s. However, modern altimetry and data from the Gravity Recovery and Climate Experiment (GRACE) mission suggest that Greenland ice mass loss has accelerated during recent years (e.g., Rignot et al. 2008; Chen et al. 2009; Velicogna 2009). This has resulted in increased freshwater fluxes into the Irminger and

DOI: 10.1175/JCLI-D-13-00762.1

(C) 2014 American Meteorological Society 
Labrador Seas. We note that in contrast to sea ice melting in the Arctic, ice sheet melting in Greenland adds mass to the ocean, which contributes significantly to global sea level rise (at a current rate of about $0.05 \mathrm{~mm} \mathrm{yr}^{-1}$; Cazenave and Llovel 2010; Church et al. 2011).

Adding meltwater in a particular region of the ocean leads to a complex response that is not just confined to variations in local sea level, but also involves the ocean circulation on many space and time scales (Stammer 2008; Stammer et al. 2011, hereafter SEA11). A relatively fast ocean response to the added mass, involving planetary waves and basin modes, occurs in terms of a barotropic global adjustment and requires weeks to months to equilibrate (e.g., Ponte 2006; Lorbacher et al. 2012). A strong dynamic ocean response to regional changes in salinity and temperature-and hence in density-also occurs in terms of long-term steric adjustments over the global domain (Stammer 2008; Lorbacher et al. 2010). However, it is less intuitive that a cooling of the sea surface temperatures (SSTs) associated with polar freshwater injection can trigger air-sea feedbacks that can cause interbasin teleconnections in sea level pressure response between the North Atlantic and the North Pacific (e.g., Okumura et al. 2009; SEA11).

Previous investigations with coupled atmosphereocean general circulation models (AOGCMs) on the response of the climate system to a freshwater perturbation have almost exclusively focused on the long term $(>10 \mathrm{yr})$ with little attention given to the early stages of adjustment. Most of these investigations have been made in the so-called waterhosing framework, in which the entire surface North Atlantic is freshened at unrealistic rates ranging between 0.1 and $1 \mathrm{~Sv}\left(1 \mathrm{~Sv}=10^{6} \mathrm{~m}^{3} \mathrm{~s}^{-1}\right)$. Moreover, the analyses have concentrated on the resulting changes in strength of the Atlantic meridional overturning circulation (AMOC). In a nutshell, waterhosing investigations have concluded that large freshwater input into the North Atlantic can lead to weakening of the AMOC and to global feedbacks, thereby affecting remote climates and their variability in different time scales (Stouffer et al. 2006; Timmermann et al. 2007; Gerdes et al. 2006; Marsh et al. 2010; Kopp et al. 2010; Weijer et al. 2012; Wang et al. 2012; An et al. 2013).

In contrast, SEA11 emphasized the effects of GIS melting on regional and global sea surface height (SSH) through processes involving both the ocean and the atmosphere. Using an AOGCM with prescribed and realistic geographical distribution of meltwater input taken as equivalent virtual salt flux, SEA11 confirmed earlier results from Stammer (2008) that adding freshwater to the ocean does not simply raise the global mean sea level, but also affects the ocean circulation and thus regional sea level. Additionally it was demonstrated that ocean-atmosphere feedbacks can significantly enhance initial sea level changes both locally and remotely. An et al. (2013) confirmed the importance of such feedbacks in a study of the impact of GIS melting on North Atlantic climate variability. Swingedouw et al. (2013) investigated the impact of $0.1-\mathrm{Sv}$ freshwater input, equally distributed around Greenland, in hindcast runs of five coupled climate models for the period 1965-2004. These authors found general agreement on several aspects of the response such as a weakening of the AMOC, warming of the Nordic seas, and cooling of the North Atlantic. The weakening of the AMOC, however, was not significant in all models. This was attributed to the different amounts of freshwater leakage into the subtropical Atlantic in the different models.

In contrast to previous studies, the focus of the present paper is on the processes that contribute to the early response of the coupled system when Greenland meltwater is added. Early is defined here as time scales from three to nine months after the meltwater perturbation is initiated. The present study is motivated by SEA11, in which the authors discussed the role of coupled ocean-atmosphere feedback processes in amplifying the long-term response to GIS melting in the North Atlantic. In their study, it was noted that the response was global from the beginning of the experiments while anomalies in the North Atlantic were mainly driven by weakening of the AMOC during the second decade after the application of GIS melting. The present study aims at identifying the mechanisms that lead to a global response within a short time after the onset of GIS melting and to discriminate the coupled atmospheric response from the from uncoupled response to the oceanic changes. Similar to SEA11, our approach is based on the comparison between AOGCM simulations without and with the same GIS melting rate prescribed in that study. In contrast to SEA11, we perform pairs of 10-member ensemble simulations allowing for a better estimate of the signal-to-noise ratio and of the significance of the simulated results. Our simulations are 50 years long, but our analyses described below center on the first simulated year, aiming to identify the early response structure, the processes involved in the atmospheric adjustment over the North Atlantic, and the associated atmospheric communication of the response to other regions.

The structure of the paper is as follows: Section 2 discusses the methodological approach, provides details about the AOGCM used, and describes the experiments performed. Section 3 examines how the ocean responds to the freshwater anomaly around Greenland: initiated in northern winter, the response is communicated to the 
atmosphere over the North Atlantic, and this communicates with the North Pacific, including atmosphereocean coupled processes. Section 3 ends up with an assessment of how the results depend on the timing of application of the melting perturbation. Section 4 concentrates on the mechanisms at work for the remote response in North Pacific to GIS melting. Section 5 provides the concluding remarks.

\section{Methods}

\section{a. The AOGCM}

Our study is based on the same configuration of the University of California-Los Angeles (UCLA) AOGCM as used by SEA11. The model consists of the UCLA atmospheric GCM (AGCM) coupled with the Massachusetts Institute of Technology (MIT) oceanic GCM (OGCM). Specifically, we use AGCM version 7.1 with a horizontal resolution of $2.5^{\circ}$ (longitude) and $2^{\circ}$ latitude, and 29 layers in the vertical (Arakawa 2001; Yu and Arakawa 2000; Konor et al. 2009). The UCLA AGCM solves the primitive equations on a sphere using the Arakawa $\mathrm{C}$ grid for horizontal discretization. The models vertical coordinate is the modified $\sigma$-coordinate described in Suarez et al. (1983), in which the lowest model layer represents the planetary boundary layer (PBL). The AGCM incorporates prognostic version of the Arakawa and Schubert (1974) parameterization of cumulus convection scheme presented by Pan and Randall (1998). The model also includes the firstgeneration Simplified Simple Biosphere model (SSiB; Xue et al. 1991) consisting of three soil layers and one vegetation layer. The distributions of sea ice, ocean surface albedo, and land surface properties (such as leaf area index, green leaf fraction, and surface roughness length) are all prescribed corresponding to a monthlymean observed climatology.

The OGCM domain is quasi-global $\left(80^{\circ} \mathrm{S}-80^{\circ} \mathrm{N}\right)$ with sea ice distribution prescribed by a monthly climatology. The zonal grid spacing is $1^{\circ}$ longitude, while the meridional ocean grid spacing is $0.3^{\circ}$ of latitude within $10^{\circ}$ of the equator increasing to $1^{\circ}$ latitude poleward of $22^{\circ} \mathrm{N}$ and $22^{\circ} \mathrm{S}$. In the vertical there are 46 ocean levels with thicknesses ranging from $10 \mathrm{~m}$ in the top $150 \mathrm{~m}$, and gradually increasing to $400-\mathrm{m}$ thickness near the maximum model depth of $5815 \mathrm{~m}$. The model bathymetry is based on ETOPO5 (Data Announcement 88MGG-02 "Digital relief of the surface of the earth," National Geophysical Data Center, Boulder, Colorado, 1988). The OGCM employs the K-profile parameterization (KPP) vertical mixing scheme of Large et al. (1994) and the isopycnal mixing schemes of Redi (1982) and Gent and McWilliams (1990) with surface tapering as per
TABLE 1. Experiments performed.

\begin{tabular}{|c|c|}
\hline Experiment & Description \\
\hline C-Control & $\begin{array}{l}10 \text { members, } 50 \text {-yr-long } \\
\text { simulations from AOGCM } \\
\text { starting } 1 \text { Jan of year } 30 \text { in } \\
\text { a spinup run }\end{array}$ \\
\hline C-Pert & $\begin{array}{l}\text { As in C-Control, except that } \\
\text { Greenland melting is added }\end{array}$ \\
\hline A-Control & $\begin{array}{l}10 \text { members, } 1-y r \text { simulation from } 1 \\
\text { Jan using SSTs from an observed, } \\
\text { monthly-mean climatology }\end{array}$ \\
\hline A-Pert & $\begin{array}{l}\text { As in A-Control, except that the } \\
\text { SSTs north of } 50^{\circ} \mathrm{N} \text { in Atlantic } \\
\text { correspond to the OGCM-only } \\
\text { run in SEA11, which included } \\
\text { Greenland melting }\end{array}$ \\
\hline C-Pert-Init & $\begin{array}{l}\text { As in C-Pert, except from } 1 \mathrm{Jul} \text { for } \\
\text { a period of } 1 \mathrm{yr}\end{array}$ \\
\hline
\end{tabular}

Large et al. (1997). Laplacian diffusion and friction are used except that horizontal friction is harmonic. Isopycnal diffusivity and isopycnal thickness diffusivity is $500 \mathrm{~m}^{2} \mathrm{~s}^{-1}$. Vertical diffusivity is $5 \times 10^{-6} \mathrm{~m}^{2} \mathrm{~s}^{-1}$. Horizontal and vertical viscosities are $10^{4}$ and $10^{-4} \mathrm{~m}^{2} \mathrm{~s}^{-1}$, respectively. No-slip bottom, free-slip lateral, and free surface boundary conditions are employed. Surface freshwater fluxes are applied as virtual salt fluxes and heat and freshwater fluxes are exchanged between the ocean and the atmosphere at an interval of 1 day. The AOGCM has been used in several studies on climate variability in addition to SEA11 (Mechoso et al. 2003; Cazes-Boezio et al. 2008; Ma et al. 2013) and in decadal climate prediction (Polkova et al. 2014).

\section{b. Control simulation}

The control experiment of the AOGCM (henceforth referred to as C-Control and described in Table 1) consists of a 10-member ensemble, 50-yr-long simulation with initial conditions taken from a long-term integration of the model (spinup). In C-Control, oceanic initial conditions correspond to 1 January of year 30 , while the atmospheric condition for each ensemble member corresponds to the dates from 27 December of year 29 to 5 January of year 30, respectively. To assess the performance of C-Control, we compare selected results from the 10-member ensemble mean for the January-March (JFM) and July-September (JAS) periods from the 31st year of the simulations with products from the Interim European Centre for Medium-Range Weather Forecasts (ECMWF) Re-Analysis (ERAInterim; Dee et al. 2011) averaged over the 21-yr period 1989-2009. The ERA-Interim dataset is available at 37 pressure levels, up to $1 \mathrm{hPa}$, and on a $0.7^{\circ} \times 0.7^{\circ}$ grid and results from an improved atmospheric model and an 

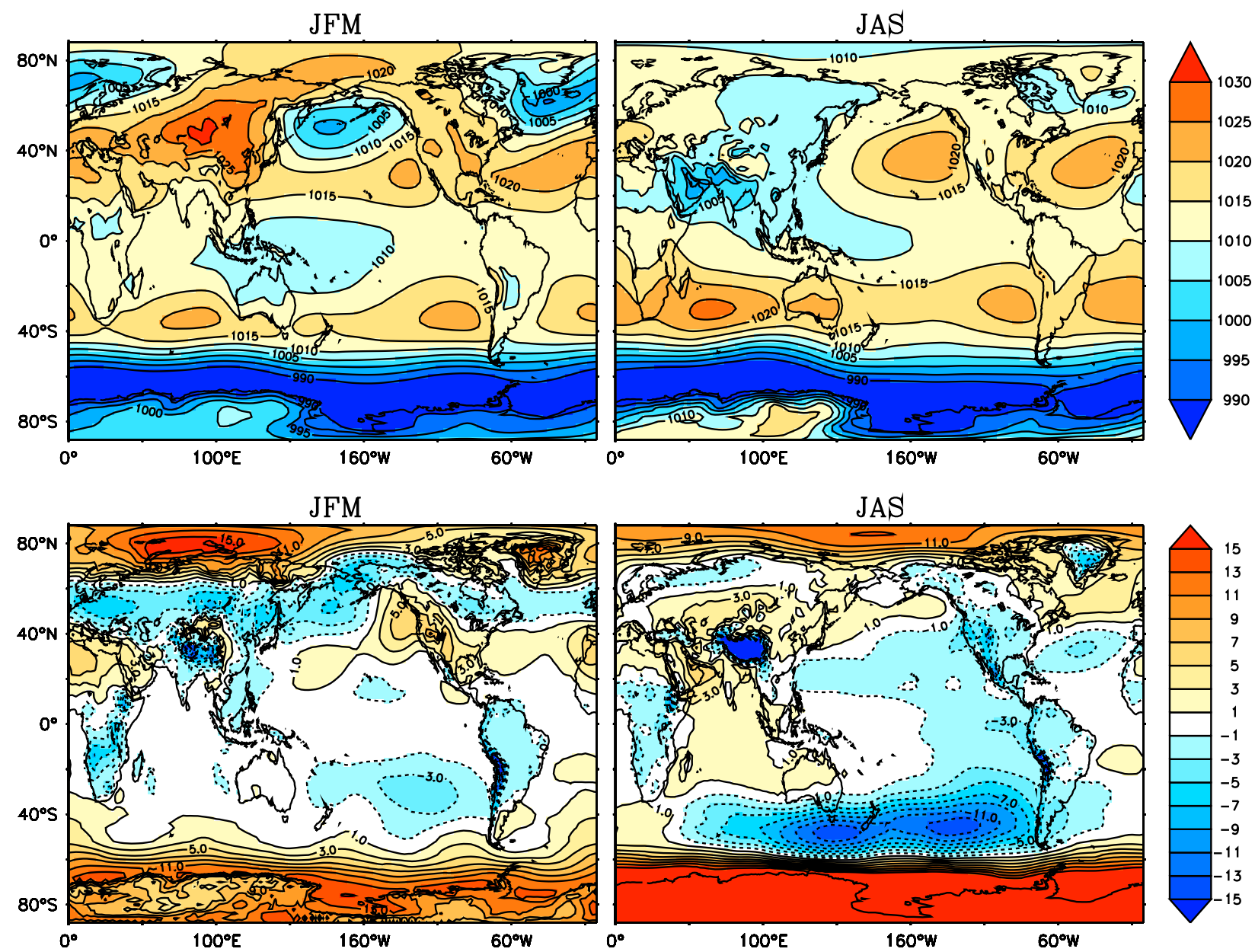

FIG. 1. (top) Mean sea level pressure (hPa) from AOGCM for (left) JFM and (right) JAS. (bottom) Mean errors (AOGCM minus ERA-Interim climatology) of sea level pressure (hPa) for (left) JFM and (right) JAS. ERA-Interim climatology corresponds to the period 1989-2009. Models climatology corresponds to the 10-member ensemble mean of first year of simulation after 30 years of spinup.

advanced four-dimensional variational data assimilation (4D-Var) technique.

The panels in the top row of Fig. 1 show the mean sea level pressure from the AOGCM for JFM and JAS. The panels in the bottom row of Fig. 1 show the corresponding simulation errors (AOGCM minus ERAInterim). (We exclude from the following discussion regions with high orography such as Greenland, the Himalayas, and Antarctica, where sea level pressure can depend strongly upon extrapolation algorithms). Figure 1 reveals that in the Northern Hemisphere the model overestimates sea level pressure (SLP) over the sea ice in the Arctic. Otherwise, error magnitudes over the oceans are mostly below $5 \mathrm{hPa}$ and therefore within the range of interannual variability. Over the North Atlantic, the magnitudes of the Iceland low and the subtropical highs are slightly overestimated in both seasons. In the North Pacific the larger errors are in JFM, when the Aleutian low is slightly deeper in the simulation while the subtropical high is stronger and centered closer to the eastern part of the Pacific. In the Southern Hemisphere, the Pacific subtropical high is underestimated in JFM, and the low pressure belt around Antarctica is overestimated. This feature corresponds to weaker westerlies at the surface in the midlatitudes. In JAS differences in sea level pressure are large over the South Pacific and Indian Oceans corresponding to weaker surface westerlies.

Overall the simulated surface wind patterns over the North Pacific and North Atlantic are consistent with the reanalysis, and the large-scale patterns associated with the major monsoons are nicely reproduced. To examine the simulated variability we show in Fig. 2 (top panels) the first two leading EOFs of JFM averaged sea level pressure from the AOGCM (10-member ensemble averaged) in the Northern Hemisphere. These two modes together represent about $67 \%$ of the total variability. Although the EOF1 in the simulation shows some 

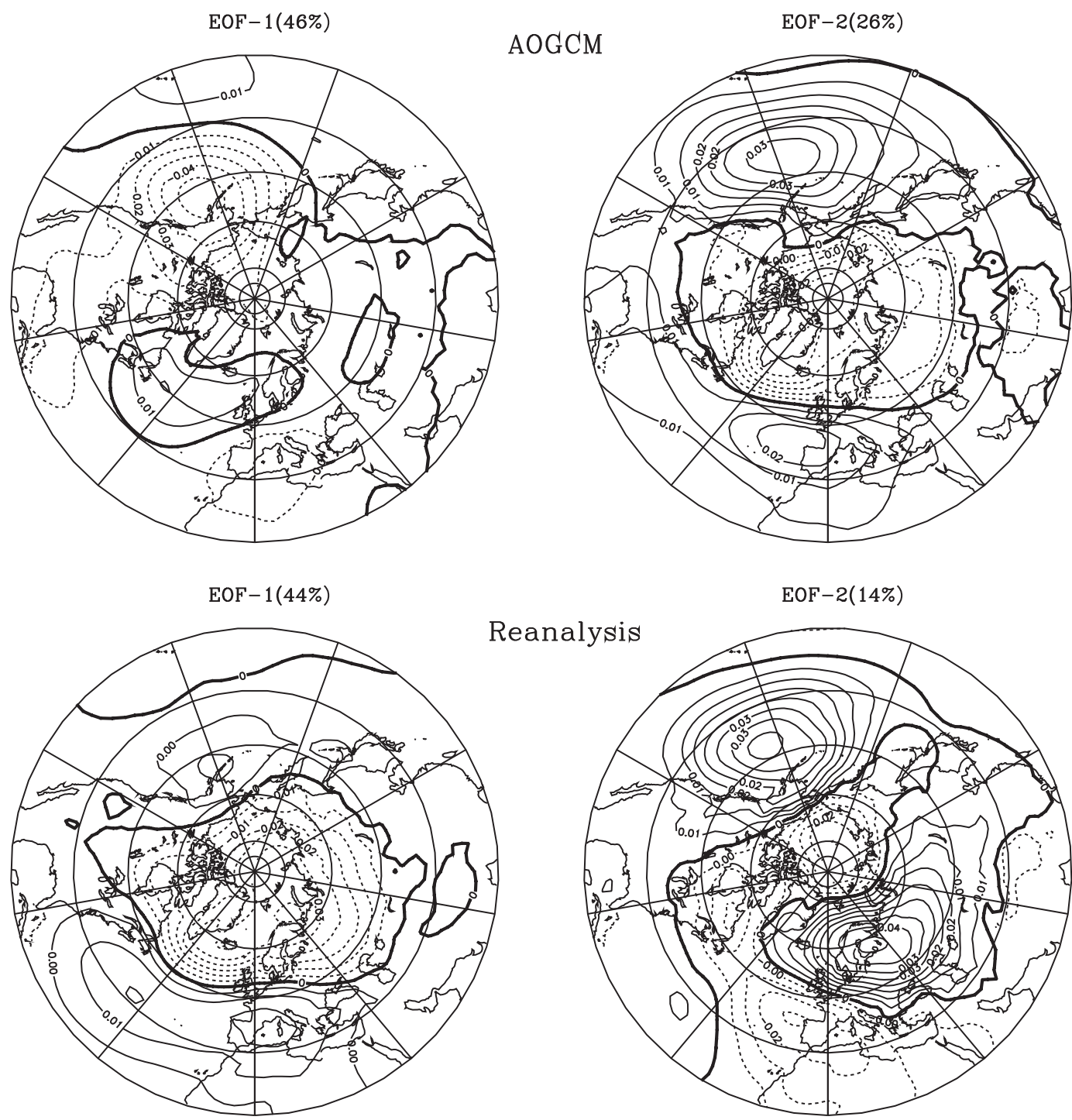

FIG. 2. First two normalized EOF modes of sea level pressure in the Northern Hemisphere from (top) C-Control and (bottom) ERA-Interim reanalysis. The EOFs were computed from mean JFM sea level pressure. For computing the EOFs, 10-member ensemble averaged C-Control runs over a 50-yr period were considered while EOFs from ERA-Interim were computed for the period 1989-2009.

resemblance to the Pacific-North American (PNA) pattern (Barnston and Livezey 1987), the center over America is shifted eastward and located over the North Atlantic. The EOF2 closely resembles the AO mode (or the northern annular mode) and explains about $26 \%$ of the total variance. In the reanalysis EOF1 corresponds to the AO (Thompson and Wallace 1998) and explains $44 \%$ of the variance (Fig. 2, bottom panel). Another clear difference between the AO pattern in the reanalysis and the simulations is that in the former the magnitudes are stronger over the Atlantic than over the Pacific, while the latter shows an opposite behavior. The pattern correlation between EOF2 of the AOGCM and the EOF1 in the reanalysis is $\sim 0.8$. Ambaum et al. (2001) and Itoh (2008) argued that North Atlantic Oscillation (NAO) and the PNA may be more physically relevant than the AO. EOF analyses performed in the Atlantic and Pacific separately consistently yield NAO and PNA patterns that can be regarded as independent oscillations, while the AO rather reflects the anticorrelation of these patterns. EOF analyses performed over the Northern Hemisphere may therefore, as seen here, provide a mix between these modes depending on how strong the anticorrelation between these two modes is. However, Rogers and McHugh (2002) argued that during seasons other than the winter season, the $\mathrm{AO}$ and 
NAO can be considered as different teleconnection patterns. During winter the AO and NAO have then been found to be inseparable, forming an annular mode (Thompson and Wallace 1998; Rogers and McHugh 2002; Feldstein and Franzke 2006). The Northern Hemisphere EOF patterns shown in Fig. 2 do represent a mix of physical modes. These results shown in Figs. 1 and 2 provide confidence on how realistic the control simulation is, which is important because the atmospheric response to perturbations is highly sensitive to the background flow (e.g., Peng et al. 1997).

\section{c. Perturbed simulations}

The experiment that will be referred to as C-Pert is a 10-member ensemble simulation from the same initial conditions as C-Control, but to which a freshwater flux perturbation is added, representing Greenland ice sheet melting. We note that the magnitude and distribution of freshwater perturbation is the same as used in SEA11 (their Fig. 1). This perturbation is consistent with a timeindependent freshwater input of $0.0275 \mathrm{~Sv}$. The perturbation magnitude is about 5 times the rate of $170 \mathrm{Gt} \mathrm{yr}^{-1}$ estimated by Luthcke et al. (2006) based on GRACE data. On the one hand, the amplitude enhancement allows us to obtain a significant response on short time scales. On the other hand, applying this factor roughly corresponds to a net freshwater discharge around Greenland projected by the end of the twenty-first century in the representative concentration pathway (RCP) 8.5 scenario (Church 2014; Schrama and Wouters 2011). In the AOGCM, the freshwater anomaly is treated as a virtual salt flux anomaly rather than a volume flux.

\section{d. Additional experiments}

Two additional ensemble experiments were carried out. One experiment aims to assess the role coupled atmosphere-ocean feedbacks play in enhancing the simulated response of the coupled system. The other simulation aims to gain further insight into the sensitivity of our results to the season initial perturbations are being applied. The first additional experiment consists of Control and Perturbed ensemble simulations using the atmospheric component of the AOGCM with prescribed SST fields (A-Control and A-Pert, respectively). The SSTs for A-Control correspond to an observed, monthly varying climatology (Reynolds et al. 2002), while the SSTs for A-Pert correspond to the first year of the OGCM-only run in SEA11 in the region around Greenland from north of $50^{\circ} \mathrm{N}$ in Atlantic and to the same values as in A-Control elsewhere. The OGCM runs made by SEA11 showed that SST perturbations due to GIS melting are confined to regions near the coast during the first few months. The second additional experiment consists of a perturbed run from initial conditions around 1 July (C-Pert-Init).

Table 1 provides a summary of the experiments performed, each consisting of a 10-member ensemble simulation. During the further course of the paper, the response to Greenland melting is analyzed in terms of differences (anomalies) in the ensemble mean of the perturbed minus the control runs. To simplify the presentation, whenever referring to the anomalies obtained in the ensemble experiments we use the following acronyms: CR: C-Pert minus C-Control; AR: A-Pert minus A-Control; and SR: C-Pert-Init minus C-Control. To assess the statistical significant of the results we apply a Student's $t$ test, for example, as described by Von Storch and Zwiers (2001). All plots showing AOGCM results in the remainder of the paper correspond to seasonal averages from the first year after the freshwater perturbation is applied.

\section{Results}

\section{a. Local response along the Greenland coast}

To illustrate the response of the ocean in the vicinity of Greenland to the prescribed freshwater injected around the continent we plot in Fig. 3a the JFM mean anomalies in sea surface salinity (SSS; contours) and in SST (shading). Most prominent is a significant negative surface salinity anomaly of $\sim 1-1.2 \mathrm{~g} \mathrm{~kg}^{-1}$ in the Denmark Strait, where the freshwater input is maximum. There are also weaker, yet significant, negative salinity anomalies in the Labrador Sea. At this location the freshwater input has another local maximum, but at least part of the ocean surface is covered by sea ice. We also recall in this context that our pattern of freshwater input corresponds to the estimated Greenland ice sheet mass loss during the period 2003-08 (updated from Luthcke et al. 2006), which shows the strongest meltwater runoff into the Denmark Strait (Fig. 1 in SEA11), but only weaker fluxes into the Labrador Sea. Present-day conditions are the opposite, with stronger runoff in the western side of Greenland (Schrama and Wouters 2011), and therefore not reflected in the runoff computed using 2003-08 data.

Coinciding with the maximum salinity anomaly in the Denmark Strait, there are negative and significant SST anomalies $\left(\sim 1^{\circ} \mathrm{C}\right)$. Long-term simulations of the ocean response to meltwater perturbations demonstrate that local surface freshening leads to a cooling of the SST, at least in part due to reduced deep convection and the associated reduction of vertical (upward) heat transport toward the surface layer of the ocean (Stouffer et al. 2006; Timmermann et al. 2007; Stammer 2008). While this holds also in our simulation over a longer time span, particularly in the Labrador Sea, it is not the main 

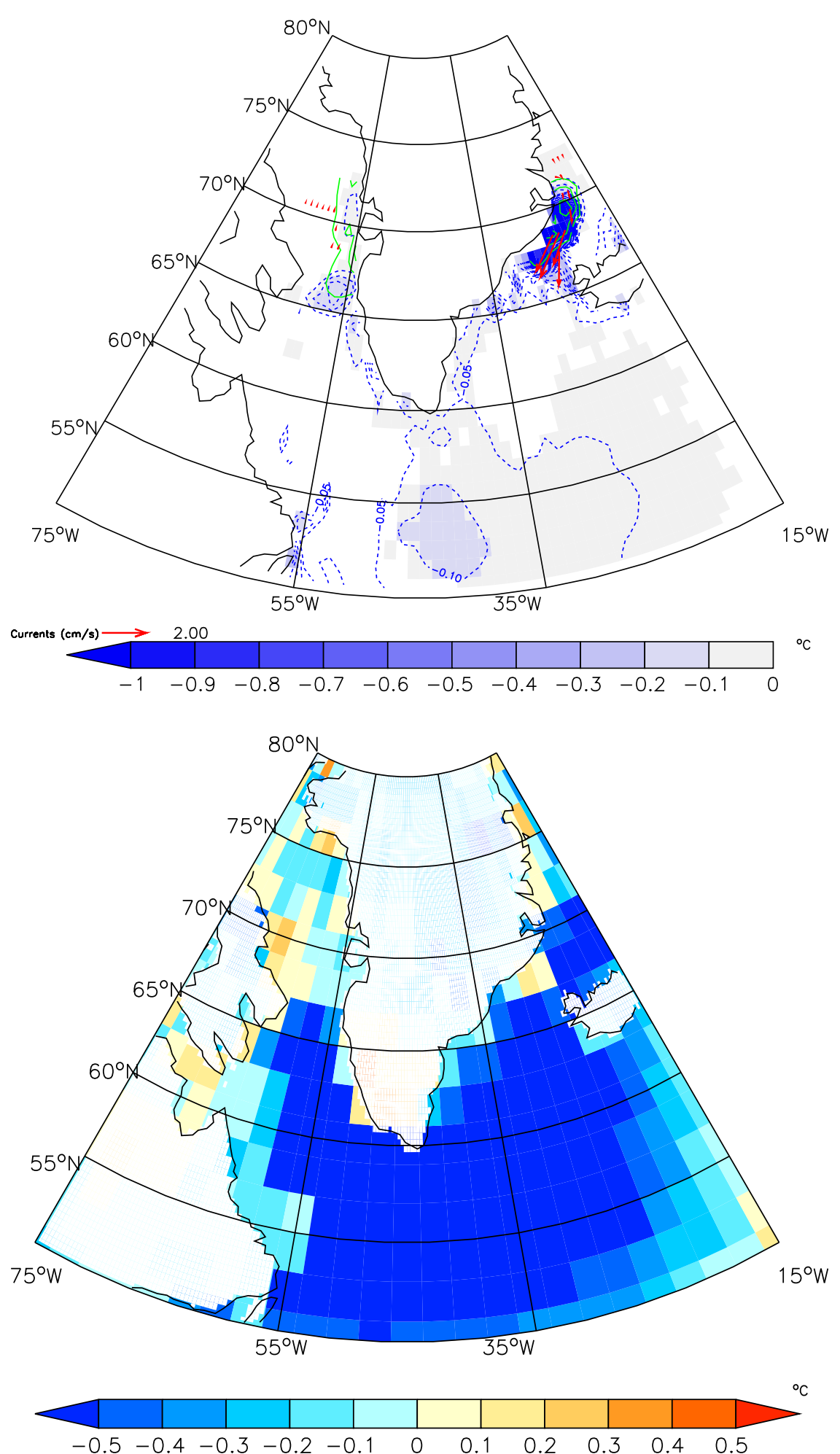

FIG. 3. (a) Mean JFM anomalies from CR of ocean surface current (red vectors, in $\mathrm{cm} \mathrm{s}^{-1}$ ) overlaid over SST (blue contours, in ${ }^{\circ} \mathrm{C}$ ) and SSS (solid green contours representing negative values, in $\mathrm{g} \mathrm{kg}^{-1}$, with a contour interval of $0.2 \mathrm{~g} \mathrm{~kg}^{-1}$ ). SST values significant at the $95 \%$ level are shaded. (b) JFM-mean boundary layer and surface temperature difference $\Delta T$. 
mechanism of the initial cooling shown in Fig. 3a. In this case, the evolution of the vertical temperature structure does not provide any evidence of anomalous vertical heat exchange during the first three months after the freshwater input is started (not shown). Instead, the freshening of the near-surface waters generates a horizontal gradient in ocean surface density, which through the thermal wind relation favors a strengthening of the East Greenland Current by $\sim 1 \mathrm{~cm} \mathrm{~s}^{-1}$ (red arrows in Fig. 3a). This, in turn, results in enhanced southward advection of cold water causing the negative SST anomaly in that region. The significant SST response, therefore, is confined to a small region near the east coast of Greenland. The SST anomalies are much smaller in the Labrador Sea, where freshening is weaker and the background flow and hydrographic conditions are different. These localized anomalies are a direct oceanic response to freshening as will be evident later in section 3d (see discussion of Fig. 8).

The sensible and latent heat flux anomalies within $45^{\circ}-66^{\circ} \mathrm{N}, 45^{\circ}-15^{\circ} \mathrm{W}$ are positive, implying that the atmosphere is gaining heat from the ocean (positive heat flux indicates ocean cooling and vice versa). To visualize the changes in the atmosphere we plot in Fig. 3b the mean JFM anomaly of difference between the SST and the temperature in the AGCM's lower layer (the PBL) from CR, which can be written as

$$
\begin{aligned}
\Delta T & =(\mathrm{PBL}-\mathrm{SST})_{P}-(\mathrm{PBL}-\mathrm{SST})_{C} \\
& =\left(\mathrm{PBL}_{P}-\mathrm{PBL}_{C}\right)-\left(\mathrm{SST}_{P}-\mathrm{SST}_{C}\right),
\end{aligned}
$$

where the subscripts $C$ and $P$ refer to C-Control and C-Pert, respectively. According to Fig. 3a, the second term on the right-hand side of Eq. (1) has large magnitude only in the Denmark Strait. In this region $\Delta T$ is positive (Fig. 3b), indicating that the cooling of the ocean is stronger than that of the atmosphere. Everywhere else $\Delta T$ is negative, indicating that the cooling of the atmosphere is stronger than the cooling of the ocean. Figures $3 \mathrm{a}$ and $3 \mathrm{~b}$ indicate that the atmospheric cooling south of Greenland is not solely caused by changes in SST. We note, however, that the values in Fig. 3b, are not significant at the $95 \%$ level, and it is difficult to make more substantiated statements on transient features with small spatial scales. Nevertheless, the following discussion of PBL wind anomalies in this region provides a justification for our interpretation of these results.

\section{b. Regional response in the North Atlantic}

It is apparent from Fig. 1 that C-Control features a well-developed Icelandic low. An enhancement of this feature through GIS melting is evident from Fig. 4a, which shows the development of significant PBL wind anomalies pointing away from the cold SST anomalies in a southeasterly direction. South of Greenland, the PBL wind anomalies enhance the westerlies from the North American continent across the North Atlantic. These wind anomalies are an integral part of an intensified low sea level pressure area centered at about $75^{\circ} \mathrm{N}, 10^{\circ} \mathrm{E}$. Since near-surface temperatures over continents in high latitudes are very low in winter, cold air advection associated with these westerly wind anomalies result in negative PBL temperature anomalies on the order of about $-1^{\circ} \mathrm{C}$ southeast of Greenland. Figure $4 \mathrm{~b}$ shows the mean JFM anomalies in geopotential height at the 300-hPa level. According to the results shown in Fig. 4b and those obtained for the boundary layer (Fig. 4a) the cyclonic circulation is strongly baroclinic with centers in the middle of Nordic seas at low levels and slightly southwest of Iceland at upper levels. Another outstanding feature in Fig. $4 \mathrm{~b}$ is the significant positive PBL temperature anomaly over western Europe (Fig. 4a), which is consistent with enhanced southwesterlies over the Atlantic Ocean. The anticyclonic anomaly over western Europe has an equivalent barotropic structure (Fig. 4b). The anomaly pattern at upper levels in the troposphere corresponds to a meandering of the mean westerly circulation and associated jet streams. We return to this point in section 4 .

\section{c. Response in the Northern Hemisphere}

Figure 5a presents the mean JFM sea level pressure anomaly in the Northern Hemisphere. This includes the lower pressure east of Greenland mentioned in subsection 3a. In addition, significant positive sea level pressure anomalies are centered at about $40^{\circ} \mathrm{N}$ and extend over the entire North Pacific Ocean. This feature corresponds to a more zonally elongated storm track from the east coast of Asia into the North Pacific (see Fig. 5b). As shown in Fig. 5b, the mean JFM zonal wind anomalies at $300 \mathrm{hPa}$ have positive and significant values $\left(>4 \mathrm{~m} \mathrm{~s}^{-1}\right)$ centered at $50^{\circ} \mathrm{N}$, and negative and significant values of about the same magnitude centered around $30^{\circ} \mathrm{N}$. Farther south from $10^{\circ} \mathrm{N}$ to the equator, there are positive wind anomalies in the central Pacific resulting in a tripole pattern over this ocean.

Altogether, this tripole pattern represents a northward shift of the westerly midlatitude jet stream in the North Pacific. The pattern in zonal wind anomalies at the 300-hPa level in the North Pacific is similar to the one at lower levels, indicating that this feature has an equivalent barotropic structure. As can be seen from Fig. 6a, the northward shift is accompanied by significant negative net surface heat flux anomalies in the western North Pacific between $20^{\circ}$ and $40^{\circ} \mathrm{N}$, which result primarily from a reduction in latent heat flux. Another 

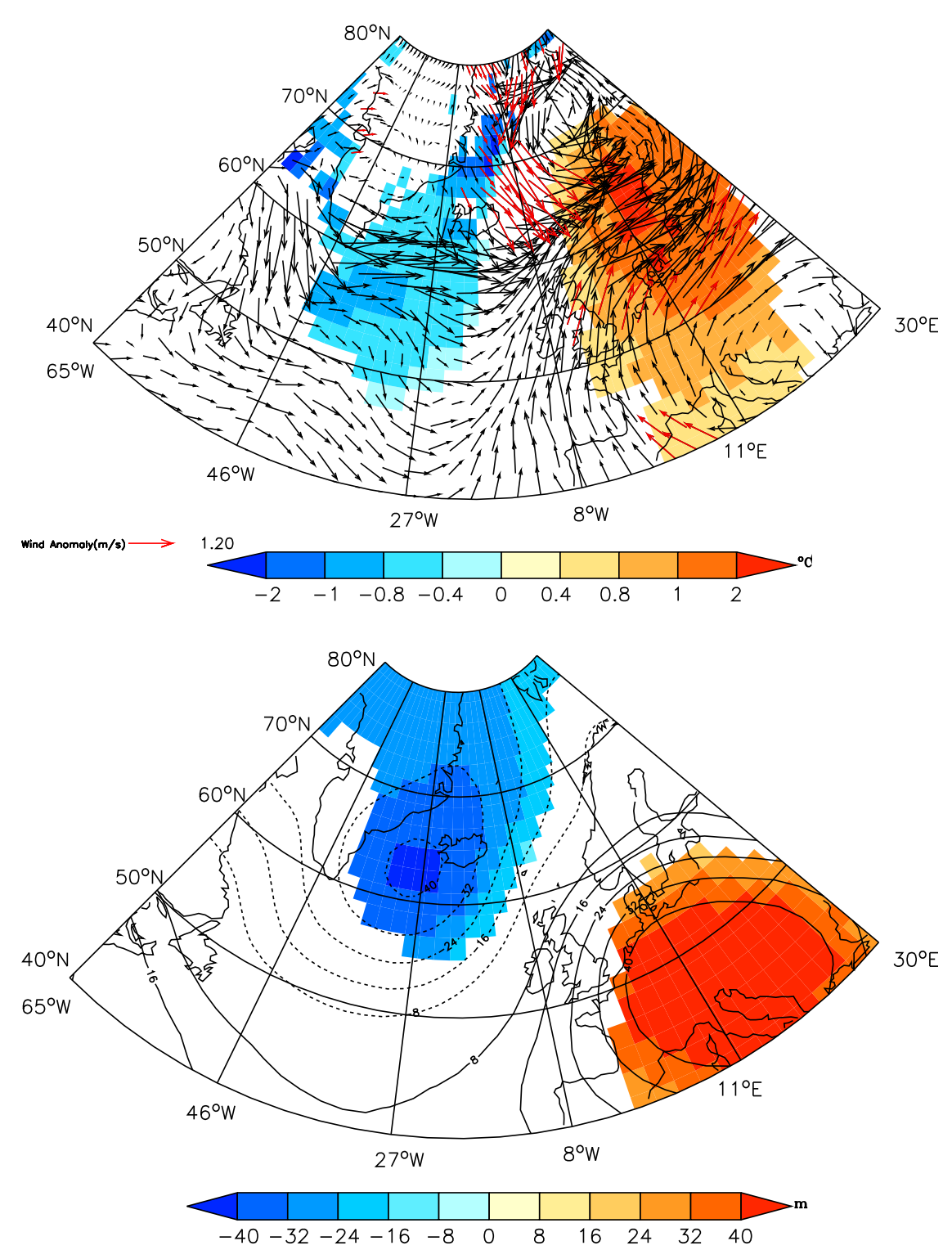

FIG. 4. Mean JFM anomalies from CR of (a) boundary layer wind (vectors, $\mathrm{m} \mathrm{s}^{-1}$ ) superimposed on atmospheric boundary layer temperature (shaded, ${ }^{\circ} \mathrm{C}$ ) and (b) geopotential height (m) at $300 \mathrm{hPa}$. Values significant at the $95 \%$ level are shaded. Red vectors are significant at the $95 \%$ level.

consequence of the latitudinal shift is the reduction in synoptic activity and associated cloud cover between $25^{\circ}$ and $35^{\circ} \mathrm{N}$, which results in increased solar insolation at the ocean surface from the subtropics in the western Pacific to the coast of California in the east. The SST anomalies (Fig. 6b) indicate a significant warming $\left(\sim 0.4^{\circ} \mathrm{C}\right)$ of the ocean surface at locations where the ocean gains heat as the latent heat loss and cloud cover are reduced. The SST anomalies are consistent with those in local surface heat flux (as seen in Fig. 6a), which are positive (into the atmosphere) at locations where SST anomalies are negative and vice versa.
Consistent with the equivalent barotropic structure of the zonal wind anomalies over the North Pacific, the mean JFM wind stress curl anomalies at the surface are negative between $30^{\circ}$ and $50^{\circ} \mathrm{N}$ and positive between $25^{\circ}$ and $30^{\circ} \mathrm{N}$ and then positive again between $5^{\circ}$ and $20^{\circ} \mathrm{N}$ (see Fig. 7a). This pattern varies seasonally, but is reproduced in the JFM of the second year (not shown). The Ekman pumping associated with these surface wind stress curl anomalies is consistent with the positive sea surface height anomaly centered at $40^{\circ} \mathrm{N}$ (Fig. 7b) and negative SSH anomalies north of $50^{\circ} \mathrm{N}$ and between equator and $20^{\circ} \mathrm{N}$. Associated anomalies in ocean heat 

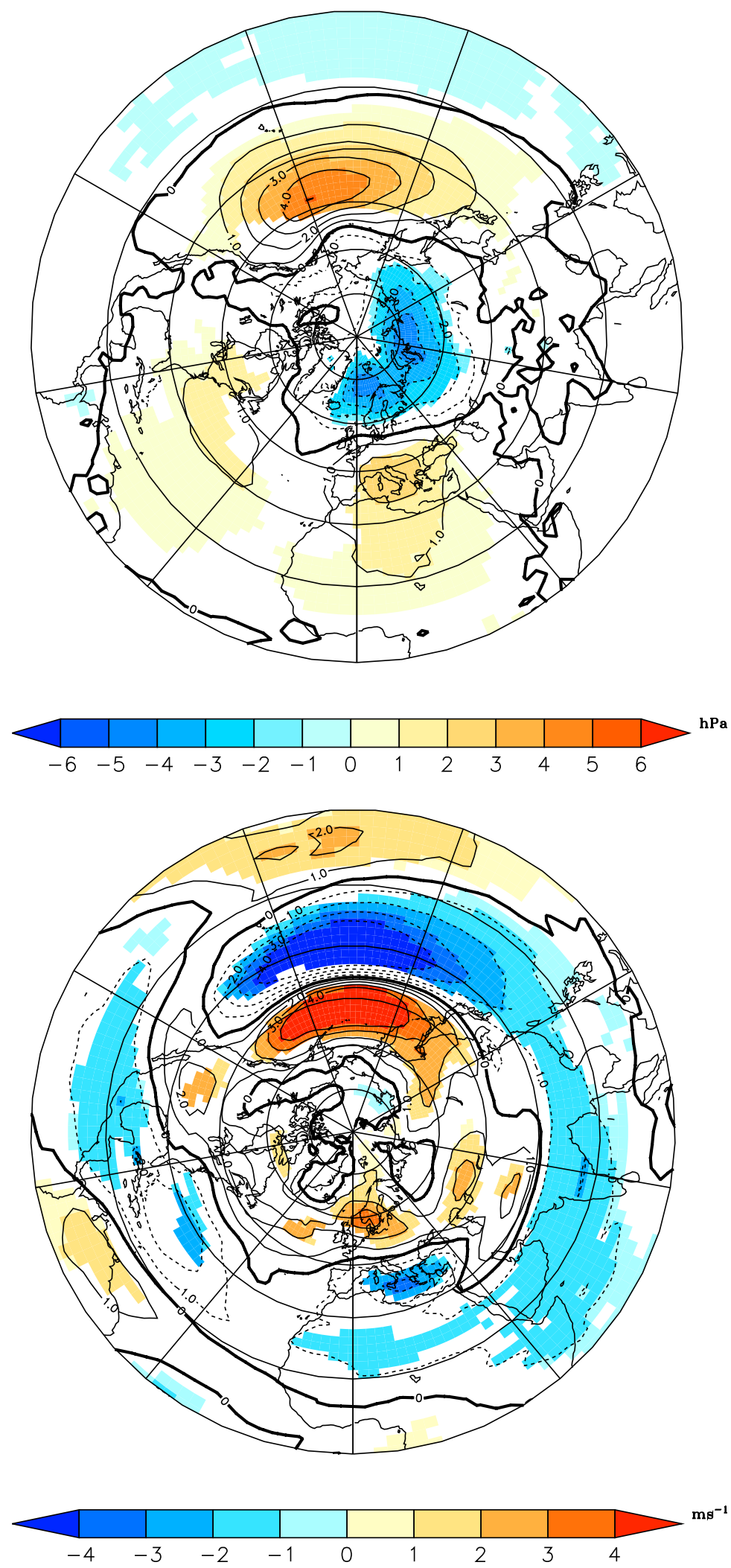

FIG. 5. Mean JFM anomalies from CR of (a) sea level pressure (hPa) and (b) zonal wind $\left(\mathrm{m} \mathrm{s}^{-1}\right)$ at $300 \mathrm{hPa}$. Values significant at the $95 \%$ level are shaded. 

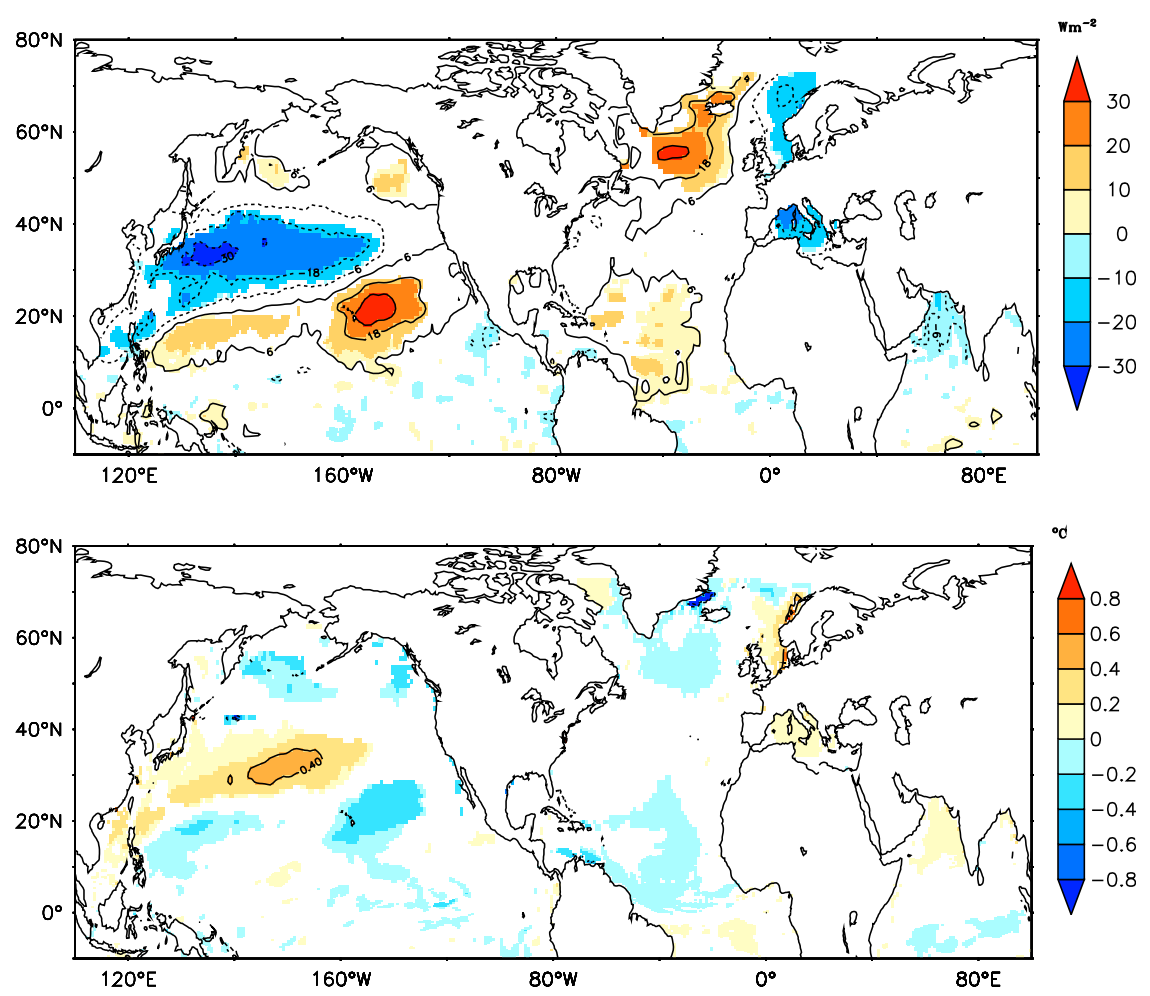

FIG. 6. Mean JFM anomalies from CR of (a) net surface heat flux $\left(\mathrm{W} \mathrm{m}^{-2}\right)$ and (b) SST $\left({ }^{\circ} \mathrm{C}\right)$. Positive net heat flux anomalies indicate ocean is losing heat (ocean cooling) and vice versa. Values significant at the $95 \%$ level are shaded.

content (surface to 500-m depth) develop in the North Pacific (not shown). In summary, during the first three months after applying the freshwater perturbation, stronger atmospheric and oceanic anomalies develop over the Pacific, making its circulation and sea level more sensitive to atmospheric climate variability as compared to the Atlantic.

\section{d. Role of coupled ocean-atmosphere feedback processes}

To assess the extent by which the coupling between the atmosphere and ocean contribute to the magnitude of the anomalies obtained in CR as shown in Figs. 5-7, we performed two 10-member ensembles of control and perturbed simulations with the atmospheric component of the AOGCM forced with prescribed SSTs (A-Control and A-Pert, respectively; see also Table 1). The JFM mean of SST anomalies around Greenland that are used in A-Pert is shown in Fig. 8. The SST anomalies are mainly confined to the Denmark Strait and have a similar magnitude to those obtained in CR (Fig. 3a). However, there are no SST anomalies south of Greenland as seen in CR. In the North Atlantic the patterns of the mean JFM response in AR are broadly similar (with a pattern correlation of 0.6 ) to those in CR; for example, as in CR (Fig. 4a), there are negative PBL temperature anomalies in AR (not shown) over the Iceland basin due to strengthening of the westerlies. Centers of low and high geopotential highs at $300 \mathrm{hPa}$ are found over Iceland and central Europe, respectively. There are also some differences between AR and CR. The negative PBL temperature anomalies are weaker (not shown) and have lesser spatial extent as compared to CR (Fig. 4a). In the mean JFM sea level pressure anomaly both AR (Fig. 9) and CR (Fig. 5a) have centers of low and high over Iceland and western Europe respectively but the magnitudes in the former simulation are clearly weaker than in the latter. Over the central North Pacific both $\mathrm{AR}$ and $\mathrm{CR}$ have positive sea level pressure anomalies. The presence of such anomalies in AR supports the hypothesis that propagation of perturbations from North Atlantic into the North Pacific is through the atmosphere and a robust response to freshwater perturbations around Greenland. However, the magnitude of these anomalies in AR is weaker $(\sim 3 \mathrm{hPa})$ and the anomaly pattern has a smaller geographical extent (Fig. 9) as compared to CR. Similarly, the zonal wind response at $300 \mathrm{hPa}$ in AR (Fig. 10a) is weaker than in $\mathrm{CR}$. The weaker response in AR can be attributed to the reduction of the oceanic contribution via atmosphere- 

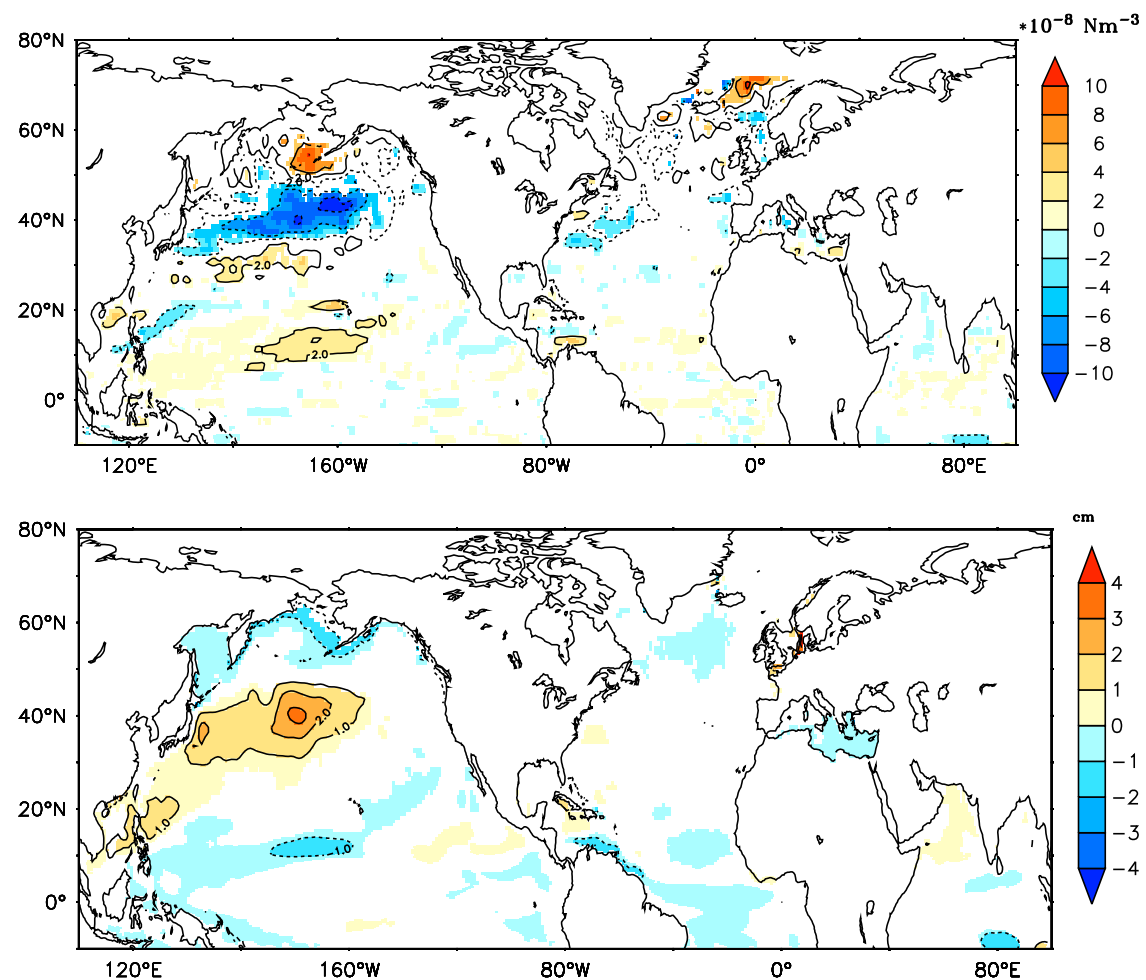

FIG. 7. As in Fig. 6, but for (a) wind stress curl $\left(\times 10^{-8} \mathrm{~N} \mathrm{~m}^{-3}\right)$ and (b) $\mathrm{SSH}(\mathrm{cm})$.

ocean interactions. This is evident from the net heat flux anomalies in AR (Fig. 12a), which are nonsignificant over the North Atlantic and much smaller over the central North Pacific as compared to CR (Fig. 6a). Since there is no feedback from the atmosphere to the ocean in AR, changes in the atmospheric circulation (as seen in Fig. 10a) in the Pacific cannot change SST. In CR, by contrast, the atmospheric high in the North Pacific induces SST anomalies, due first to the convergence of heat via Ekman pumping (Fig. 7a) and second to changes in latent heat flux related to the reduced surface zonal wind (Fig. 5b). The changes in SST cause several feedback mechanisms. Although higher SST is likely to cause upward surface heat flux anomalies that damp the SST anomaly, this effect remains too small to be visible. The response of the atmospheric circulation to the SST anomaly is analogous to the mechanism described by Latif and Barnett (1994), who showed that a SST anomaly in the North Pacific similar to Fig. 6b leads to high pressure over the North Pacific, which tends to reinforce the anomalous high. Additionally, higher SST cause changes in cloud cover (section 3c). Negative cloud anomalies across Pacific result in warmer SST due to increased shortwave heat flux. According to Park et al. (2006) the warm SST caused by reduction in cloud cover can result in positive feedback leading to persistence of North Pacific SST anomalies. The positive cloud anomalies in the eastern Pacific have resulted in cold SST anomalies, which in turn can further increase cloudiness (Norris and Leovy 1994).

\section{e. Sensitivity to timing of perturbation}

Since the perturbations in the AOGCM runs discussed so far were applied starting around 1 January in the northern winter, an obvious question is whether the response in the first three months would be different if the freshwater perturbations had been applied starting early in the northern summer. To address this question, we performed an additional ensemble of simulations from initial conditions around 1 July (C-Pert-Init; see Table 1).

During the first months of the simulation, SR produces localized SST anomalies in the Denmark Strait similar to those obtained in CR; however, magnitudes are weaker and the atmospheric response in the North Atlantic is absent. The SST anomalies in the Denmark Strait become stronger with time. In the atmosphere, negative boundary layer temperature anomalies develop in the same region. Unlike in CR, the negative boundary layer temperature anomalies south of Greenland are absent and surface westerlies in the region do not strengthen. This provides further evidence that the 


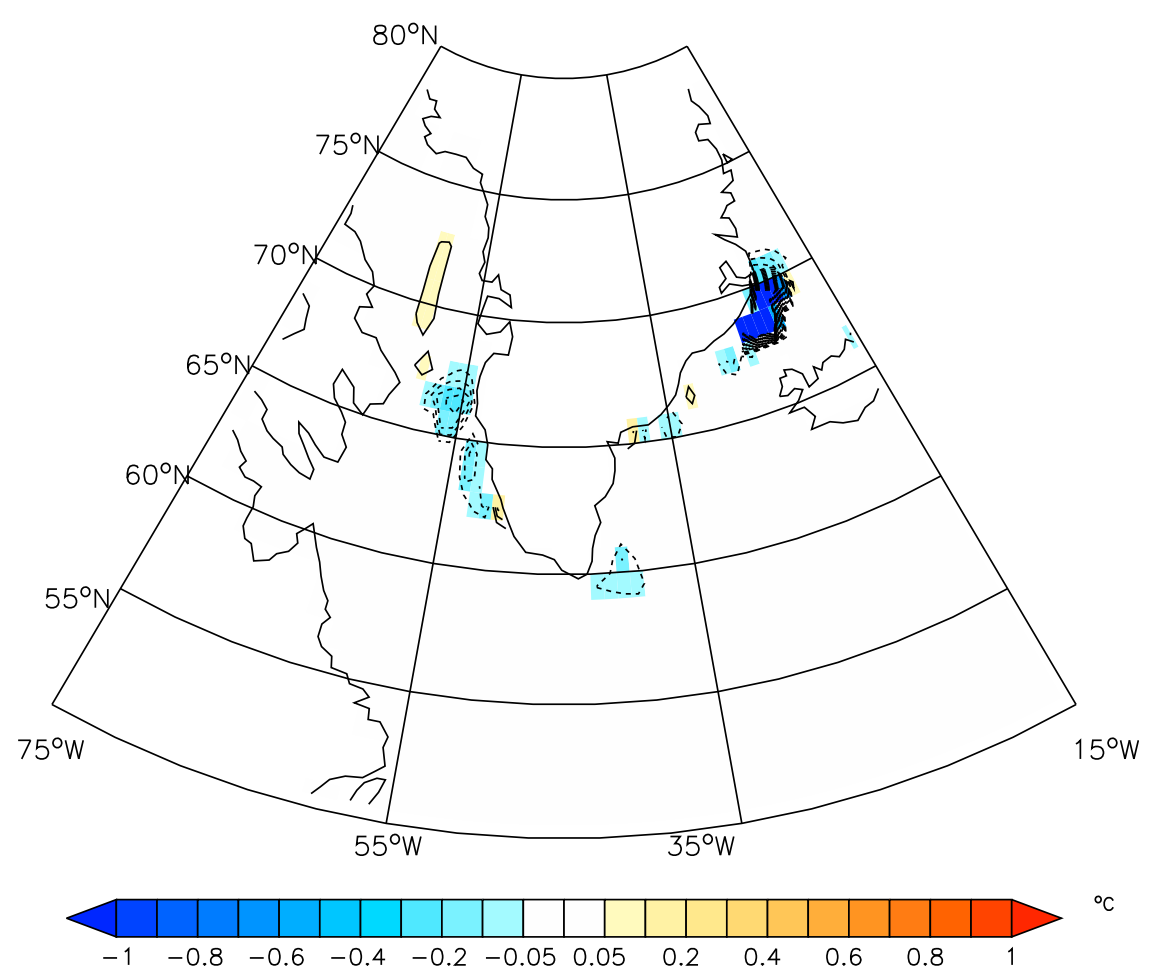

FIG. 8. Contours of mean JFM (first year after perturbation) SST anomalies $\left({ }^{\circ} \mathrm{C}\right)$ from SEA11 used in A-Pert. Anomalies greater than \pm 0.05 are shaded.

initial SST anomaly is an ocean-only feature. In the North Pacific, up to the first 5 months of simulation corresponding to Northern Hemisphere summer and fall, there are no significant anomalies either in the zonal wind or in sea level pressure, and the effect of freshening is mainly confined to the region around Greenland. During subsequent months (the following JFM season), in comparison to the corresponding anomalies from CR (Fig. 5a), the low and high pattern of the mean JFM sea level pressure anomalies in the North Atlantic are shifted slightly southward, while over the North Pacific the response features are remarkably similar (Fig. 11). The difference in magnitude of anomalies in the North Atlantic can be attributed to the difference in SST anomalies in SR, which now result from more than 6 months of melting and consequently have spread along the entire southern coast of Greenland (not shown). Particularly at the location where the SST anomaly first appeared in summer, the SST has cooled down further. In comparison to $\mathrm{CR}$, the zonal wind anomalies at the 300-hPa level strengthen in the North Atlantic (Fig. 10b); in the North Pacific, however, the northward shift of the westerly flow is similar to that in CR. There are negative and significant net surface heat flux anomalies in the western North Pacific between $20^{\circ}$ and $40^{\circ} \mathrm{N}$, which result primarily from a reduction in latent heat flux (Fig. 12b). These patterns of JFM net heat flux anomalies in the North Pacific are also quite similar to those obtained in CR (Fig. 6a), except that in SR there are significant positive anomalies in the eastern Pacific along the coast of North America. The confinement of the response to the North Atlantic in summer and fall, and the extension to the North Pacific in winter is consistent with the intensification of the westerly circulation and its influence on the establishment of teleconnections (e.g., Hoskins and Karoly 1981).

\section{Teleconnection between the North Atlantic and North Pacific}

In section 3, we demonstrated that the simulated AOGCM response to GIS melting is significant at the $95 \%$ level. It remains to be examined how such a largescale response, which entails modifications of the air-sea fluxes over large geographical regions, can be produced by perturbation along the periphery of Greenland for which the significant SST anomalies are highly localized as shown in Fig. 3a. In this section we explore the mechanisms by which localized oceanic perturbations induced by GIS meltwater can result in large-scale perturbations over the North Atlantic and eventually the entire Northern Hemisphere. 

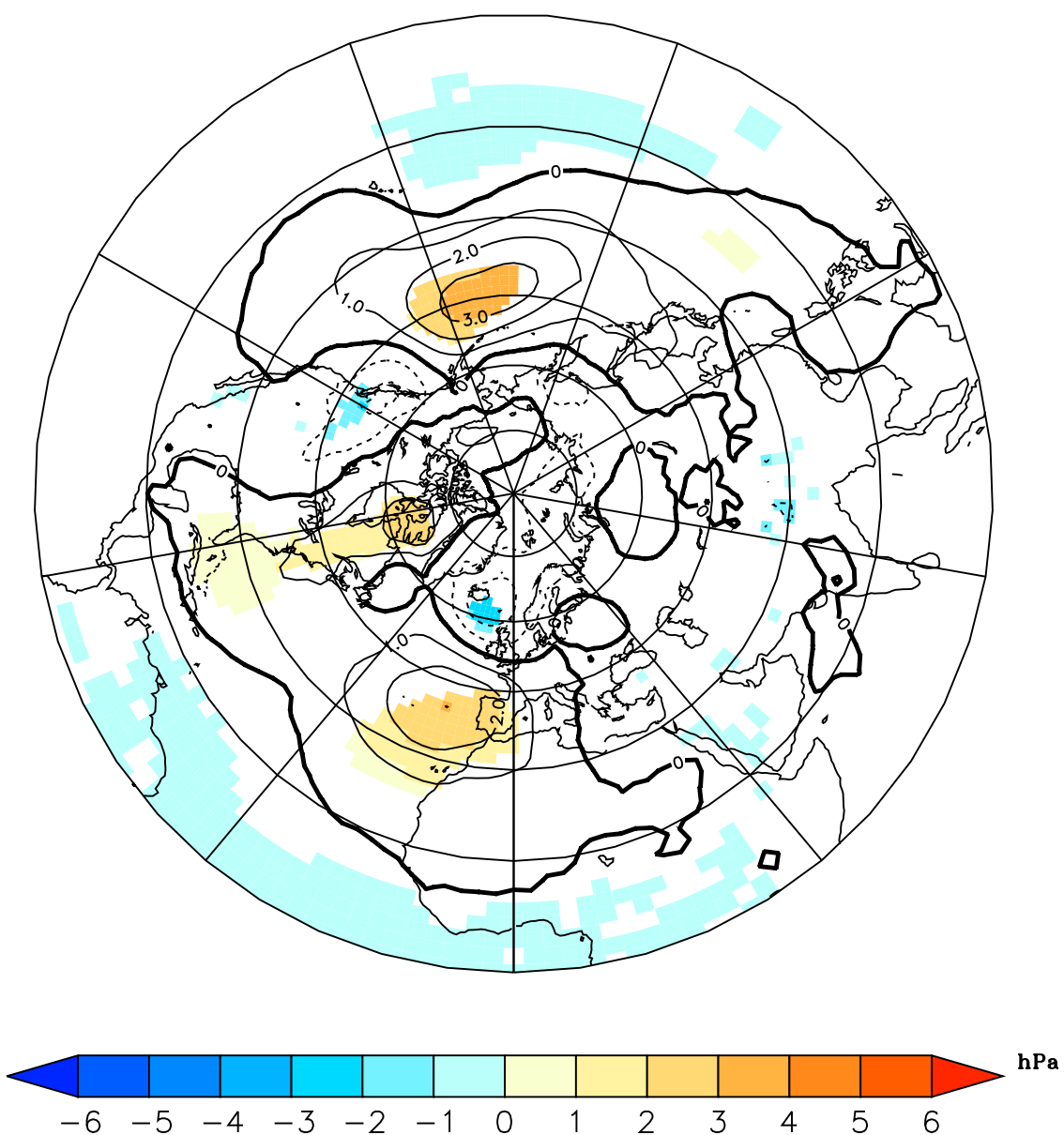

FIG. 9. Mean JFM anomalies from AR of sea level pressure (hPa). Values significant at the $95 \%$ level are shaded.

Our hypothesis is that the response corresponds to one of the major internal modes of variability in the northern atmosphere. In the Northern Hemisphere the most prominent spatial modes of variability include the NAO, PNA, and AO and their interrelation was discussed earlier in section $2 \mathrm{~b}$. Although these modes are known to be generated internally in the coupled oceanatmosphere system, they may also respond to external forcing, for example, volcanic eruptions (Christiansen 2008) or to sea ice and SST variability (Frankignoul et al. 2014; Deser et al. 2007). However, an alternative hypothesis could be that the response from the North Atlantic into the North Pacific primarily results from teleconnection associated with Rossby wave propagation. In the following paragraphs we discuss both options, noting that both are not entirely independent.

To look into the modes of model internal variability, we refer once again to the EOFs of simulated mean JFM sea level pressure shown in Fig. 2. EOF2 patterns (which closely resemble the AO mode) are broadly similar to the patterns of sea level pressure anomalies in CR (Fig. 5). There are however, some discrepancies. First, the positive center over the eastern tropical Atlantic in the EOF2 (Fig. 2, top right) is missing in the CR; instead, in Fig. 5a there are two positive centers, one over western North Atlantic and the other over the Mediterranean. Second, the negative center placed over Greenland in EOF2 is shifted eastward in CR. Despite these differences, the similarities between EOF2 and Fig. 5a are strong enough to justify our claim that freshening around Greenland excites internal modes variability of the atmospheric circulation simulated by the AOGCM similar to the AO/NAO mode.

Several authors have considered the existence of a connection between the North Atlantic and the North Pacific. Rogers and McHugh (2002), for example, discuss the winter NAO/AO inseparability as a possible effect of a shared winter storm track between the northeastern Atlantic and the Arctic. In this context, it is also relevant to consider the anticorrelation between the 

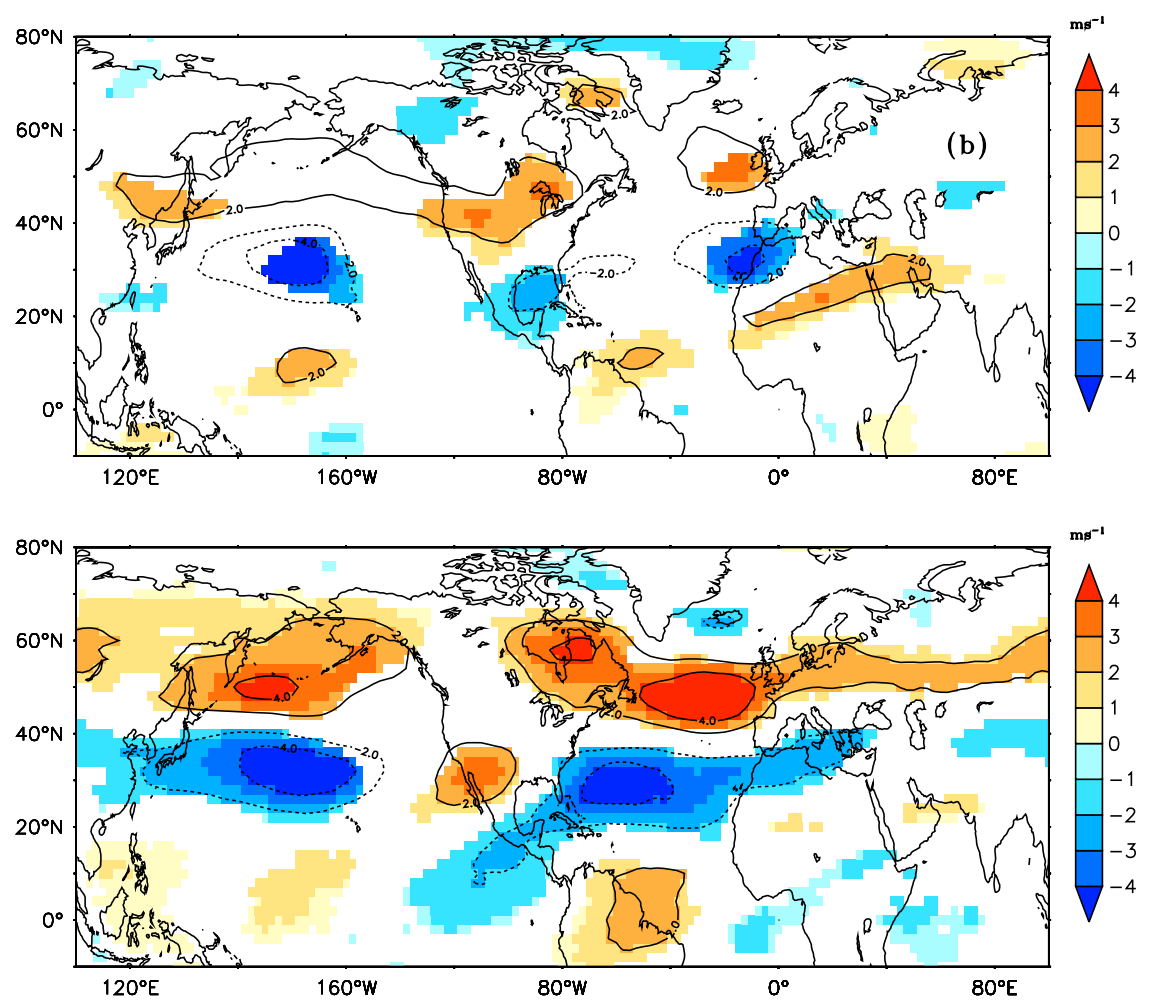

FIG. 10. Mean JFM anomalies of zonal wind $\left(\mathrm{m} \mathrm{s}^{-1}\right.$ ) at $300 \mathrm{hPa}$ from (a) AR and (b) SR. Values significant at the $95 \%$ level are shaded.

NAO and the PNA including the relevant physical processes. Particularly, the question where the center of action of this relation lies is of interest. Pinto et al. (2011) examined the results of three coupled GCMs (CGCMs) and found that the intensity of the anticorrelation varies on multidecadal time scales. Phases of large anticorrelation, which resemble AO patterns and therefore also Fig. 5a, are found to originate from the PNA. The connection between PNA and NAO is established as warm and moist air from the Gulf of Mexico and cold air from Canada associated with the PNA enhance growth conditions for eddies at the entrance of the North Atlantic storm track and hence influence the NAO. As the pattern of Fig. 5a originates from the North Atlantic no such feature over the North American continent can be seen in our results.

Another plausible explanation of the remote response in the Pacific is based upon teleconnections with the North Atlantic. In mid and high latitudes, teleconnections tend to be dominated by an equivalent barotropic signal because vertical propagation tends to reduce the contribution of baroclinic modes (Held and Kang 1987). Thus, barotropic models have been widely used to study the teleconnection response at midlatitudes (e.g., Hoskins and Karoly 1981; Simmons 1982; Simmons et al. 1983; Held and Kang 1987). As indicated in section 3c, perturbations over the Pacific are equivalent barotropic.

A first-order approximation to the teleconnections from the North Atlantic can be obtained by interpreting the intensification of the Iceland low as a "Rossby wave source" (Sardeshmukh and Hoskins 1988), and per Hoskins and Karoly (1981) this source could potentially propagate a perturbation via Rossby wave into the $\mathrm{Pa}$ cific. However, since the SST anomaly is small in extent and the amplitude barely reaches $1^{\circ} \mathrm{C}$, the interpretation of the teleconnections as a linear response from a local heat source is less likely to hold-particularly because the dominant change in heat flux is, as Fig. 6a shows, despite a cold SST anomaly a warming rather than a cooling of the atmosphere.

\section{Discussion and conclusions}

We have investigated the transient, large-scale global response of a coupled ocean-atmosphere model to a meltwater anomaly around Greenland. For meltwater perturbations started in January, the immediate response to GIS melting corresponds to the intensification of the Icelandic low. This is associated with the generation of stronger surface wind away from the Greenland coast above colder SSTs in the Denmark Strait. The 

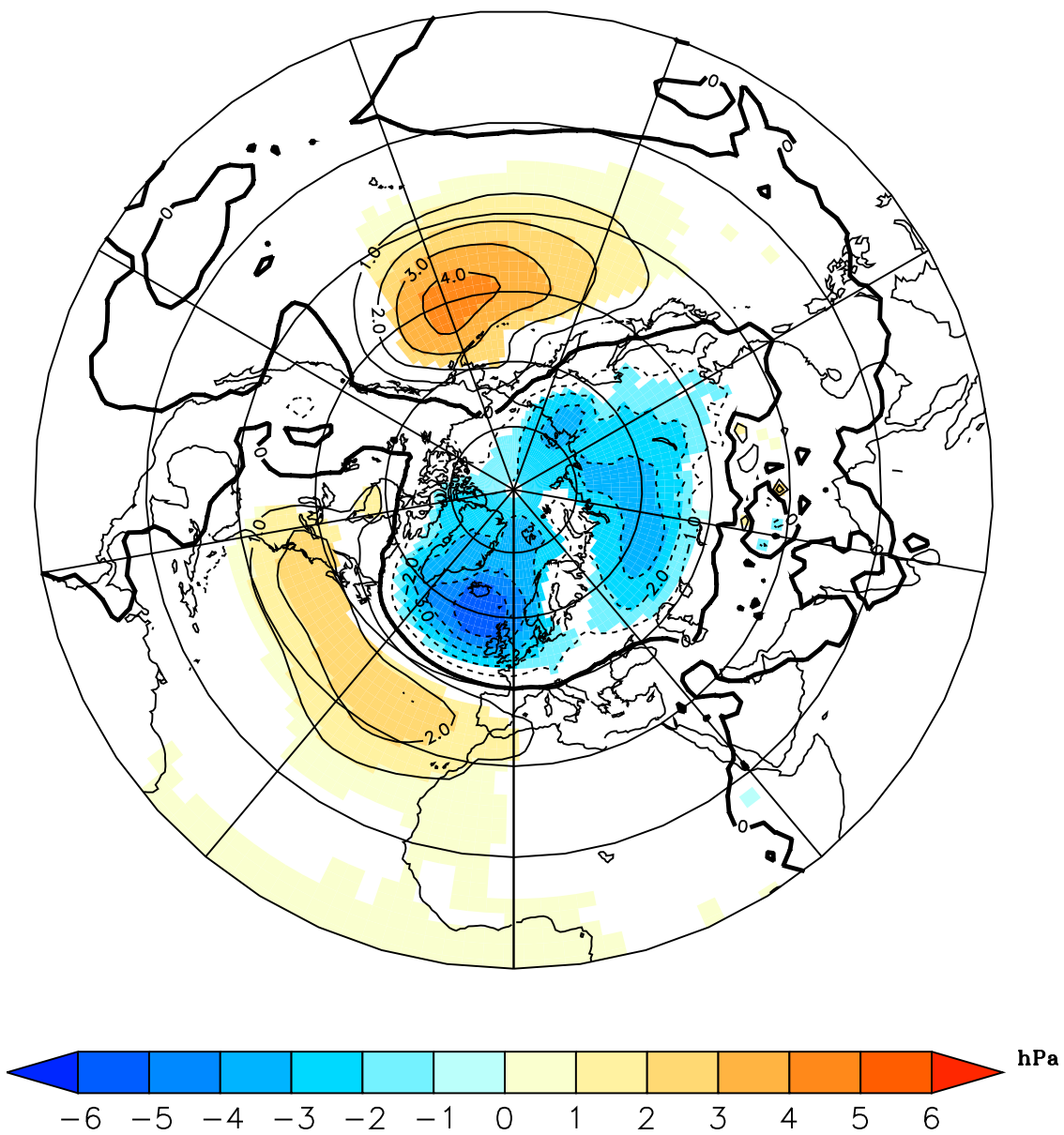

FIG. 11. As in Fig. 9, but from SR.

structure of the atmospheric response is highly baroclinic and resembles that described by Deser et al. (2007) in a large ensemble of simulations with the National Center for Atmospheric Research (NCAR) Community Climate Model version 3 (CCM3) forced by sea ice extent anomalies in the North Atlantic sector. Deser et al. (2007) obtained an immediate (5-10 days) baroclinic response caused by the diabatic heating associated with surface heat flux anomalies. Within 2-3 months the response in the atmosphere became more barotropic. In our case, we obtain a similar, albeit slower, evolution with the mean JFM fields still showing a baroclinic structure. It is plausible that this difference in time scales is due to a slower rate at which our perturbation is applied. We find a teleconnection to the North Pacific that is established via the atmosphere resulting in SST and SSH anomalies. Moreover, atmosphere-ocean interactions appear to play a significant role in enhancing the resulting amplitude of anomalies outside of the North Atlantic.

Using an ensemble of perturbed-control simulations with only the atmospheric component of the AOGCM with prescribed SSTs, we found evidence that coupled atmosphere-ocean processes significantly contribute to the response generated over the North Atlantic and North Pacific. To explore the sensitivity of our results to initial conditions, we examined whether the mean JFM results vary if the ensemble simulations start on 1 January or six months earlier. A summer start of the meltwater perturbation results in weak atmospheric anomalies during the first three months. In the subsequent winter, however, the anomalies are similar to those obtained from a winter start, except for stronger amplitudes due to the extra time for the accumulation of freshwater.

The resemblance of the sea level pressure anomaly patterns to the AO pattern indicates that the freshwater forcing could excite one of the dominant modes of variability in the Northern Hemisphere atmosphere, specifically the AO/NAO. We further explore the plausible mechanism for the remote impact of melting based on Rossby wave propagation from the North Atlantic. Although this could explain the eastward propagation 

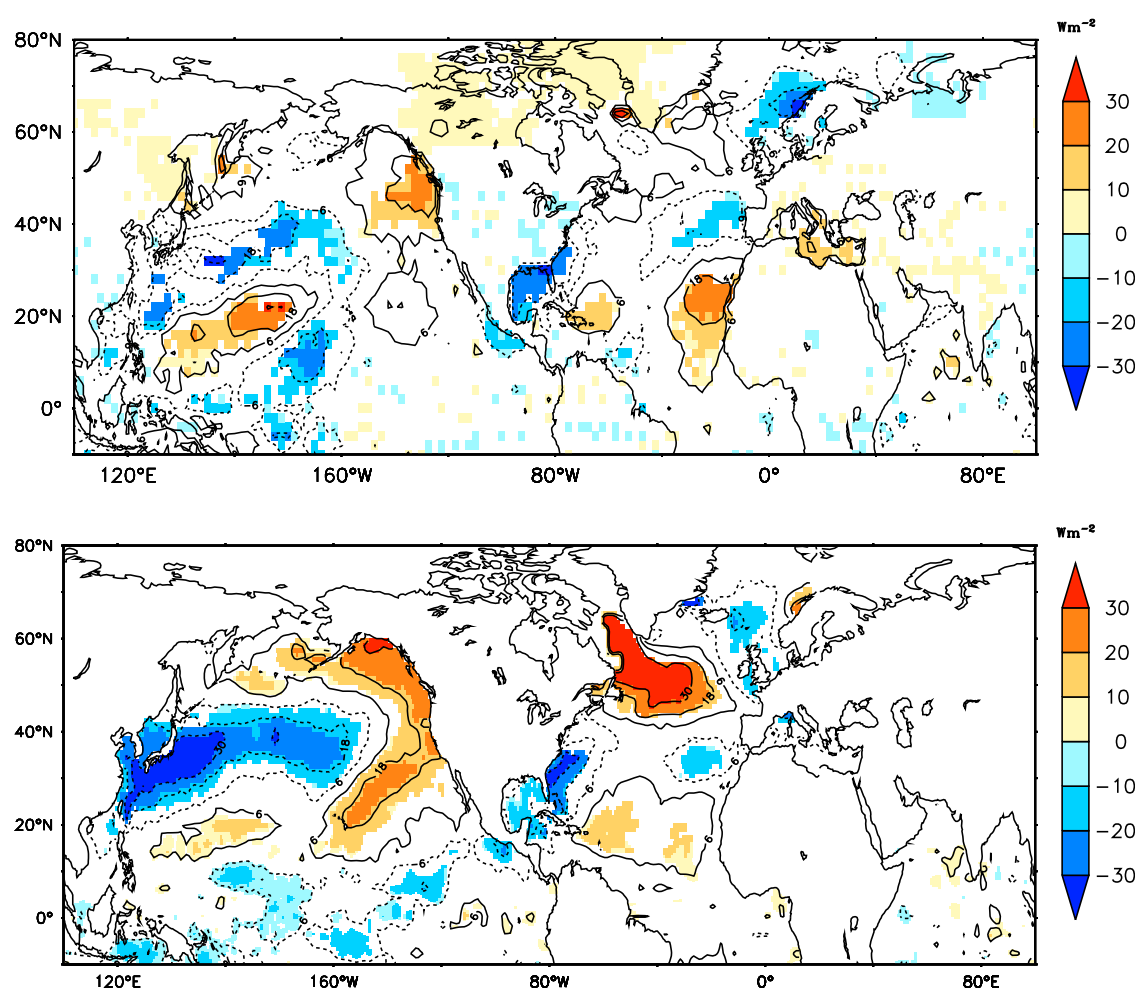

FIG. 12. Mean JFM anomalies of net surface heat flux $\left(\mathrm{W} \mathrm{m}^{-2}\right)$ from (a) AR and (b) SR. Positive net heat flux anomalies indicate ocean is losing heat (ocean cooling). Values significant at the $95 \%$ level are shaded.

across Europe and Asia, generating equivalent barotropic anomalies over western Europe and North Pacific, given the size of the initial SST anomaly this is unlikely the main mechanism for explaining the patterns.

We further note that, while in our study the driving force was the ocean freshening in the North Atlantic caused by GIS melting, other events of coupled atmosphere-ocean variability that involve SST anomalies may as well cause a similar response of the coupled system on time scales that are short as compared to those of the events themselves. Examples may include great salinity anomalies (GSA; e.g., Dickson et al. 1988; Belkin et al. 1998) or other processes leading to salinity anomalies, such as changes in sea ice extent (Deser et al. 2007; Frankignoul et al. 2014), which are part of natural variability but may also be affected by a changing climate. The GSA events recorded in the twentieth century show that they originated from north of Iceland through a freshwater pulse from the Arctic in the 1960s (Dickson et al. 1988), while the 1980s and 1990s events formed more locally in the Labrador Sea with freshwater contributions for the Canadian Archipelago (Belkin et al. 1998; Belkin 2004). Since those events already entail the advection of colder temperatures (unlike as in our case where the advection of cold water is induced by
Greenland melting), the impact on the ocean should be at least as large as that originating from Greenland melting. Reanalysis datasets and in situ observations can be used to estimate the impact of the GSA events on the atmosphere. The time series of near-surface salinities at Fylla Bank in the West Greenland Current (adopted from Köhl and Serra 2014) as an updated version of Reverdin et al. (1997) shown in Fig. 13a illustrates the three large events of freshwater anomalies in the 1970s, 1980s, and 1990s. The correlation between anomalies in salinity (negative corresponding to fresher water) and in SST (Fig. 13b) displays the associated signal of cold water not only in the region of the East and West Greenland currents, but also over the entire subpolar North Atlantic as noted in our perturbation experiments (Fig. 3a). Our simulations, however, do not capture an additional albeit smaller signature of cold SST in the subtropical North Atlantic and North Pacific.

Similar to Fig. 4a, the response of the atmospheric circulation to GSA events is illustrated via the perturbation in geopotential height at $300 \mathrm{hPa}$. Associated with the colder and fresher surface water near Greenland is a pattern of low pressure north of Iceland and another center of high pressure farther south (Fig. 13c). The correlation is largest for zero lag and remains 

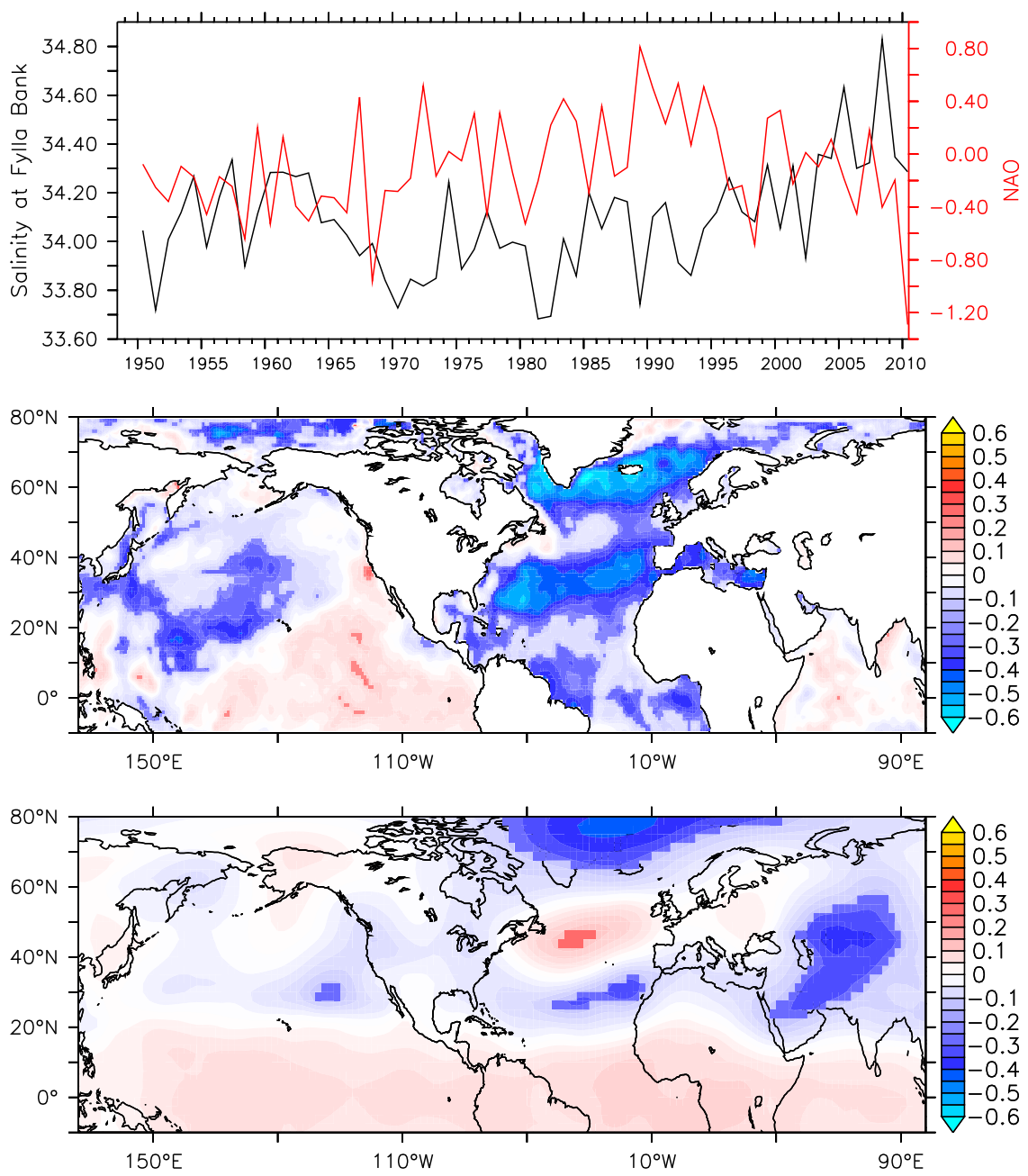

FIG. 13. (a) Salinity time series at Fylla Bank $\left(64^{\circ} \mathrm{N}, 54^{\circ} \mathrm{W}\right)$ from Köhl and Serra (2014), with the NAO index from the Climate Prediction Center, National Oceanic and Atmospheric Administration (NOAA), superimposed. The correlation of freshwater (negative salinity) at Fylla Bank with (b) annual mean values from the Hadley Centre Sea Ice and Sea Surface Temperature dataset (HadISST) and (c) JFM mean geopotential height at $300 \mathrm{hPa}$ from the $40-\mathrm{yr}$ ECMWF Re-Analysis (ERA-40). The correlations significant at the $90 \%$ level are shown by fully saturated color.

similar if salinity is leading but reverses sign if the atmosphere is leading. This feature resembles the other one shown in Fig. 5a, which was associated to the NAO. We can therefore hypothesize that the advection of cold and freshwater associated with the GSAs contributes to the variability of the NAO, leading to higher NAO states. The relation between GSA and NAO has been discussed in the context of the impact of the atmospheric circulation on the formation of the GSA. For instance, Dickson et al. (1996) argued that the GSA in the 1960s is concurrent with the record low intensity of the NAO in the 1960s. Furthermore, Sundby and Drinkwater (2007) showed that GSAs occurred during negative NAO phases, which were suggested to modify the volume fluxes in and out of the Arctic. In the present paper we argue that perturbations such as the GSAs can contribute to the high NAO phases. A direct correlation between the NAO time series and the freshwater anomalies shown in Fig. 13a yields a positive value of $r=0.24$ (significant at a $95 \%$ level; $r=0.29$ for 3 -yr means). These correlations are not high enough to argue that GSAs cause high NAO states, but together with the results from the perturbation experiments they suffice to contend that GSA have contributed to the strength of the NAO.

Finally we highlight three findings of this work on the early effects of GIS melting. First, a mechanism is proposed for the impact of the melting based on oceanic perturbations amplified by atmosphere-ocean 
interactions without any contribution from anomalies in oceanic convection. Second, GIS-induced anomalies in the North Atlantic trigger anomalies in the Pacific through atmospheric teleconnections, the latter being enhanced by atmosphere-ocean interactions. Third, GSAs (or GIS melting) can contribute to the NAO variability in the northern winter. These findings suggest that a proper representation of hydrological processes in the North Atlantic and Arctic in climate models may be of importance for climate forecasts, not only on long time scales but also on seasonal to interannual time scales.

Acknowledgments. This work was funded in part through a Max Planck Society (MPG) Fellowship to D. Stammer, the Special Research Program (SPP 1257) "Mass transports and distribution in the Earth System" funded by Deutsche Forschungs Gemeinschaft (DFG), and the BMBF (Federal Ministry of Education and Science) Project REAL-GOCE. CRM acknowledges financial support through the CliSAP Excellence Cluster of the University of Hamburg, funded through the DFG. Additional funding was provided by the National Science Foundation Grant AGS 1041477 at UCLA. This is a contribution to the Integrated Climate Analysis and Prediction (CliSAP) Excellence Cluster.

\section{REFERENCES}

Ambaum, M. H., B. J. Hoskins, and D. B. Stephenson, 2001: Arctic Oscillation or North Atlantic Oscillation? J. Climate, 14, 3495-3507, doi:10.1175/1520-0442(2001)014<3495: AOONAO $>2.0 . \mathrm{CO} ; 2$.

An, S.-I., H. Kim, and B.-M. Kim, 2013: Impact of freshwater discharge from the Greenland Ice Sheet on North Atlantic climate variability. Theor. Appl. Climatol., 112, 29-43, doi:10.1007/ s00704-012-0699-6.

Arakawa, A., 2001: A personal perspective on the early years of general circulation modeling at UCLA. Int. Geophys., 70, 1-65, doi:10.1016/S0074-6142(00)80049-2.

— , and W. H. Schubert, 1974: Interaction of a cumulus cloud ensemble with the large-scale environment, Part I. J. Atmos. Sci., 31, 674-701, doi:10.1175/1520-0469(1974)031<0674: IOACCE $>2.0 . \mathrm{CO} ; 2$.

Barnston, A. G., and R. E. Livezey, 1987: Classification, seasonality, and persistence of low-frequency atmospheric circulation patterns. Mon. Wea. Rev., 115, 1083-1126, doi:10.1175/ 1520-0493(1987)115<1083:CSAPOL > 2.0.CO;2.

Belkin, I. M., 2004: Propagation of the "Great Salinity Anomaly" of the 1990s around the northern North Atlantic. Geophys. Res. Lett., 31, L08306, doi:10.1029/2003GL019334.

— - S. Levitus, J. Antonov, and S.-A. Malmberg, 1998: "Great Salinity Anomalies" in the North Atlantic. Prog. Oceanogr., 41, 1-68, doi:10.1016/S0079-6611(98)00015-9.

Cazenave, A., and W. Llovel, 2010: Contemporary sea level rise. Annu. Rev. Mar. Sci., 2, 145-173, doi:10.1146/ annurev-marine-120308-081105.

Cazes-Boezio, G., D. Menemenlis, and C. R. Mechoso, 2008: Impact of ecco ocean-state estimates on the initialization of seasonal climate forecasts. J. Climate, 21, 1929-1947, doi:10.1175/2007JCLI1574.1.

Chen, J., C. Wilson, D. Blankenship, and B. Tapley, 2009: Accelerated Antarctic ice loss from satellite gravity measurements. Nat. Geosci., 2, 859-862, doi:10.1038/ngeo694.

Christiansen, B., 2008: Volcanic eruptions, large-scale modes in the Northern Hemisphere, and the El Niño-Southern Oscillation. J. Climate, 21, 910-922, doi:10.1175/2007JCLI1657.1.

Church, J. A., 2014: The evidence shows sea levels are rising: Let's not be caught out. Ecos, 2014 (193). [Available online at http:// www.ecosmagazine.com/paper/EC14052.htm.]

— , and Coauthors, 2011: Revisiting the earth's sea-level and energy budgets from 1961 to 2008. Geophys. Res. Lett., 38, L18601, doi:10.1029/2011GL048794.

Dee, D., and Coauthors, 2011: The Era-Interim reanalysis: Configuration and performance of the data assimilation system. Quart. J. Roy. Meteor. Soc., 137, 553-597, doi:10.1002/qj.828.

Deser, C., R. A. Tomas, and S. Peng, 2007: The transient atmospheric circulation response to North Atlantic SST and sea ice anomalies. J. Climate, 20, 4751-4767, doi:10.1175/JCLI4278.1.

Dickson, R., J. Meincke, S.-A. Malmberg, and A. J. Lee, 1988: The "great salinity anomaly" in the northern North Atlantic 1968-1982. Prog. Oceanogr., 20,103-151, doi:10.1016/ 0079-6611(88)90049-3.

_ term coordinated changes in the convective activity of the North Atlantic. Prog. Oceanogr., 38, 241-295, doi:10.1016/ S0079-6611(97)00002-5.

Feldstein, S. B., and C. Franzke, 2006: Are the North Atlantic Oscillation and the northern annular mode distinguishable? J. Atmos. Sci., 63, 2915-2930, doi:10.1175/JAS3798.1.

Frankignoul, C., N. Sennéchael, and P. Cauchy, 2014: Observed atmospheric response to cold season sea ice variability in the Arctic. J. Climate, 27, 1243-1254, doi:10.1175/ JCLI-D-13-00189.1.

Gent, P. R., and J. C. McWilliams, 1990: Isopycnal mixing in ocean circulation models. J. Phys. Oceanogr., 20, 150-155, doi:10.1175/1520-0485(1990)020<0150:IMIOCM > 2.0.CO;2.

Gerdes, R., W. Hurlin, and S. M. Griffies, 2006: Sensitivity of a global ocean model to increased run-off from Greenland. Ocean Modell., 12, 416-435, doi:10.1016/j.ocemod.2005.08.003.

Held, I., and I. Kang, 1987: Barotropic models of the extratropical response to El Niño. J. Atmos. Sci., 44, 3576-3586, doi:10.1175/ 1520-0469(1987)044<3576:BMOTER > 2.0.CO;2.

Hoskins, B. J., and D. J. Karoly, 1981: The steady linear response of a spherical atmosphere to thermal and orographic forcing. J. Atmos. Sci., 38, 1179-1196, doi:10.1175/1520-0469(1981)038<1179: TSLROA $>2.0 . \mathrm{CO} ; 2$.

Itoh, H., 2008: Reconsideration of the true versus apparent Arctic Oscillation. J. Climate, 21, 2047-2062, doi:10.1175/2007JCLI2167.1.

Köhl, A., and N. Serra, 2014: Causes of decadal changes of the freshwater content in the Arctic Ocean. J. Climate, 27, 34613475, doi:10.1175/JCLI-D-13-00389.1.

Konor, C. S., G. C. Boezio, C. R. Mechoso, and A. Arakawa, 2009: Parameterization of PBL processes in an atmospheric general circulation model: Description and preliminary assessment. Mon. Wea. Rev., 137, 1061-1082, doi:10.1175/ 2008MWR2464.1.

Kopp, R., J. Mitrovica, S. Griffies, J. Yin, C. Hay, and R. Stouffer, 2010: The impact of Greenland melt on regional sea level: A preliminary comparison of dynamic and static equilibrium effects. Climatic Change Lett., 103, 619-625, doi:10.1007/ s10584-010-9935-1. 
Large, W. G., J. C. McWilliams, and S. C. Doney, 1994: Oceanic vertical mixing: A review and a model with a nonlocal boundary layer parameterization. Rev. Geophys., 32, 363-403, doi:10.1029/94RG01872.

_ - G. Danabasoglu, S. C. Doney, and J. C. McWilliams, 1997: Sensitivity to surface forcing and boundary layer mixing in a global ocean model: Annual-mean climatology. J. Phys. Oceanogr., 27, 2418-2447, doi:10.1175/1520-0485(1997)027<2418: $\mathrm{STSFAB}>2.0 . \mathrm{CO} ; 2$.

Latif, M., and T. P. Barnett, 1994: Causes of decadal climate variability over the North Pacific and North America. Science, 266, 634-637, doi:10.1126/science.266.5185.634.

Lorbacher, K., J. Dengg, C. W. Böning, and A. Biastoch, 2010: Regional patterns of sea level change related to interannual variability and multidecadal trends in the Atlantic meridional overturning circulation. J. Climate, 23, 4243-4254, doi:10.1175/ 2010JCLI3341.1.

_ , S. J. Marsland, J. A. Church, S. M. Griffies, and D. Stammer, 2012: Rapid barotropic sea level rise from ice sheet melting. J. Geophys. Res., 117, C06003, doi:10.1029/2011JC007733.

Luthcke, S. B., and Coauthors, 2006: Recent Greenland ice mass loss by drainage system from satellite gravity observations. Science, 314, 1286-1289, doi:10.1126/science.1130776.

Ma, H.-Y., C. R. Mechoso, Y. Xue, H. Xiao, J. D. Neelin, and X. Ji, 2013: On the connection between continental-scale land surface processes and the tropical climate in a coupled oceanatmosphere-land system. J. Climate, 26, 9006-9025, doi:10.1175/ JCLI-D-12-00819.1.

Marsh, R., D. Desbruyères, J. Bamber, B. de Cuevas, A. Coward, and Y. Aksenov, 2010: Short-term impacts of enhanced Greenland freshwater fluxes in an eddy-permitting ocean model. Ocean Sci., 6, 749-760, doi:10.5194/os-6-749-2010.

Mechoso, C. R., J. D. Neelin, and J.-Y. Yu, 2003: Testing simple models of ENSO. J. Atmos. Sci., 60, 305-318, doi:10.1175/ 1520-0469(2003)060<0305:TSMOE $>2.0 . C O ; 2$.

Norris, J. R., and C. B. Leovy, 1994: Interannual variability in stratiform cloudiness and sea surface temperature. J. Climate, 7, 1915-1925, doi:10.1175/1520-0442(1994)007<1915: IVISCA $>2.0 . \mathrm{CO} ; 2$.

Okumura, Y. M., C. Deser, A. Hu, A. Timmermann, and S.-P. Xie, 2009: North Pacific climate response to freshwater forcing in the subarctic North Atlantic: Oceanic and atmospheric pathways. J. Climate, 22, 1424-1445, doi:10.1175/2008JCLI2511.1.

Pan, D.-M., and D. D. Randall, 1998: A cumulus parameterization with a prognostic closure. Quart. J. Roy. Meteor. Soc., 124, 949-981, doi:10.1002/qj.49712454714.

Park, S., M. A. Alexander, and C. Deser, 2006: The impact of cloud radiative feedback, remote ENSO forcing, and entrainment on the persistence of North Pacific sea surface temperature anomalies. J. Climate, 19, 6243-6261, doi:10.1175/ JCLI3957.1.

Peng, S., W. A. Robinson, and M. P. Hoerling, 1997: The modeled atmospheric response to midlatitude SST anomalies and its dependence on background circulation states. J. Climate, 10, 971-987, doi:10.1175/1520-0442(1997)010<0971: TMARTM $>2.0 . \mathrm{CO} ; 2$.

Perovich, D., W. Meier, M. Tschudi, S. Gerland, and J. RichterMenge, 2013: Sea ice cover [in "State of the Climate in 2012"]. Bull. Amer. Meteor. Soc., 94, S126-S127.

Pinto, J. G., M. Reyers, and U. Ulbrich, 2011: The variable link between PNA and NAO in observations and in multi-century CGCM simulations. Climate Dyn., 36, 337-354, doi:10.1007/ s00382-010-0770-x.
Polkova, I., A. Köhl, and D. Stammer, 2014: Impact of initialization procedures on the predictive skill of a coupled oceanatmosphere model. Climate Dyn., 42, 3151-3169, doi:10.1007/ s00382-013-1969-4.

Ponte, R. M., 2006: Oceanic response to surface loading effects neglected in volume-conserving models. J. Phys. Oceanogr., 36, 426-434, doi:10.1175/JPO2843.1.

Redi, M. H., 1982: Oceanic isopycnal mixing by coordinate rotation. J. Phys. Oceanogr., 12, 1154-1158, doi:10.1175/ 1520-0485(1982)012<1154:OIMBCR > 2.0.CO;2.

Reverdin, G., D. Cayan, and Y. Kushnir, 1997: Decadal variability of hydrography in the upper northern North Atlantic in 19481990. J. Geophys. Res., 102, 8505-8531, doi:10.1029/ 96JC03943.

Reynolds, R. W., N. A. Rayner, T. M. Smith, D. C. Stokes, and W. Wang, 2002: An improved in situ and satellite SST analysis for climate. J. Climate, 15, 1609-1625, doi:10.1175/ 1520-0442(2002)015<1609:AIISAS > 2.0.CO;2.

Rignot, E., J. L. Bamber, M. R. van den Broeke, C. Davis, Y. Li, W. J. van de Berg, and E. van Meijgaard, 2008: Recent Antarctic ice mass loss from radar interferometry and regional climate modelling. Nat. Geosci., 1, 106-110, doi:10.1038/ngeo102.

Rogers, J., and M. McHugh, 2002: On the separability of the North Atlantic Oscillation and Arctic Oscillation. Climate Dyn., 19, 599-608, doi:10.1007/s00382-002-0247-7.

Sardeshmukh, P. D., and B. J. Hoskins, 1988: The generation of global rotational flow by steady idealized tropical divergence. J. Atmos. Sci., 45, 1228-1251, doi:10.1175/1520-0469(1988)045<1228: TGOGRF $>2.0 . \mathrm{CO} ; 2$.

Schrama, E. J., and B. Wouters, 2011: Revisiting Greenland Ice Sheet mass loss observed by GRACE. J. Geophys. Res., 116, B02407, doi:10.1029/2009JB006847.

Shepherd, A., and Coauthors, 2012: A reconciled estimate of icesheet mass balance. Science, 338, 1183-1189, doi:10.1126/ science.1228102.

Simmons, A., 1982: The forcing of stationary wave motion by tropical diabatic heating. Quart. J. Roy. Meteor. Soc., 108, 503534, doi:10.1002/qj.49710845703.

_ agation and instability, and atmospheric teleconnection patterns. J. Atmos. Sci., 40, 1363-1392, doi:10.1175/1520-0469 (1983) $040<1363$ :BWPAIA $>2.0$. CO;2.

Stammer, D., 2008: Response of the global ocean to Greenland and Antarctic ice melting. J. Geophys. Res., 113, C06022, doi:10.1029/2006JC004079.

—, N. Agarwal, P. Herrmann, A. Köhl, and C. Mechoso, 2011: Response of a coupled ocean-atmosphere model to Greenland ice melting. Surv. Geophys., 32, 621-642, doi:10.1007/ s10712-011-9142-2.

Stocker, T. F., and Coauthors, Eds., 2014: Climate Change 2013: The Physical Science Basis. Cambridge University Press, 1535 pp.

Stouffer, R., and Coauthors, 2006: Investigating the causes of the response of the thermohaline circulation to past and future climate changes. J. Climate, 19, 1365-1387, doi:10.1175/ JCLI3689.1.

Suarez, M. J., A. Arakawa, and D. A. Randall, 1983: The parameterization of the planetary boundary layer in the UCLA general circulation model: Formulation and results. Mon. Wea. Rev., 111, 2224-2243, doi:10.1175/1520-0493(1983)111<2224: ТРОТРВ $>2.0 . \mathrm{CO} ; 2$.

Sundby, S., and K. Drinkwater, 2007: On the mechanisms behind salinity anomaly signals of the northern North Atlantic. Prog. Oceanogr., 73, 190-202, doi:10.1016/j.pocean.2007.02.002. 
Swingedouw, D., and Coauthors, 2013: Decadal fingerprints of freshwater discharge around Greenland in a multi-model ensemble. Climate Dyn., 41, 695-720, doi:10.1007/s00382-012-1479-9.

Thompson, D. W., and J. M. Wallace, 1998: The Arctic Oscillation signature in the wintertime geopotential height and temperature fields. Geophys. Res. Lett., 25, 1297-1300, doi:10.1029/ 98GL00950.

Timmermann, A., and Coauthors, 2007: The influence of a weakening of the Atlantic meridional overturning circulation on ENSO. J. Climate, 20, 4899-4919, doi:10.1175/JCLI4283.1.

Velicogna, I., 2009: Increasing rates of ice mass loss from the Greenland and Antarctic Ice Sheets revealed by GRACE. Geophys. Res. Lett., 36, L19503, doi:10.1029/2009GL040222.

Von Storch, H., and F. W. Zwiers, 2001: Statistical Analysis in Climate Research. Cambridge University Press, 484 pp.

Wang, X., Q. Wang, D. Sidorenko, S. Danilov, J. Schröter, and T. Jung, 2012: Long-term ocean simulations in FESOM:
Evaluation and application in studying the impact of Greenland Ice Sheet melting. Ocean Dyn., 62, 1471-1486, doi:10.1007/s10236-012-0572-2.

Weijer, W., M. E. Maltrud, M. W. Hecht, H. A. Dijkstra, and M. A. Kliphuis, 2012: Response of the Atlantic Ocean circulation to Greenland Ice Sheet melting in a strongly-eddying ocean model. Geophys. Res. Lett., 39, L09606, doi:10.1029/ 2012 GL051611.

Xue, Y., P. Sellers, J. Kinter, and J. Shukla, 1991: A simplified biosphere model for global climate studies. J. Climate, 4, 345-364, doi:10.1175/1520-0442(1991)004<0345: ASBMFG $>2.0 . \mathrm{CO} ; 2$.

Yu, J., and A. Arakawa, 2000: A coupled GCM pilgrimage: From climate catastrophe to ENSO simulations. General Circulation Model Development: Past, Present, and Future: Proceedings of a Symposium in Honor of Professor Akio Arakawa, D. Randall, Ed., Academic Press, 539-575. 